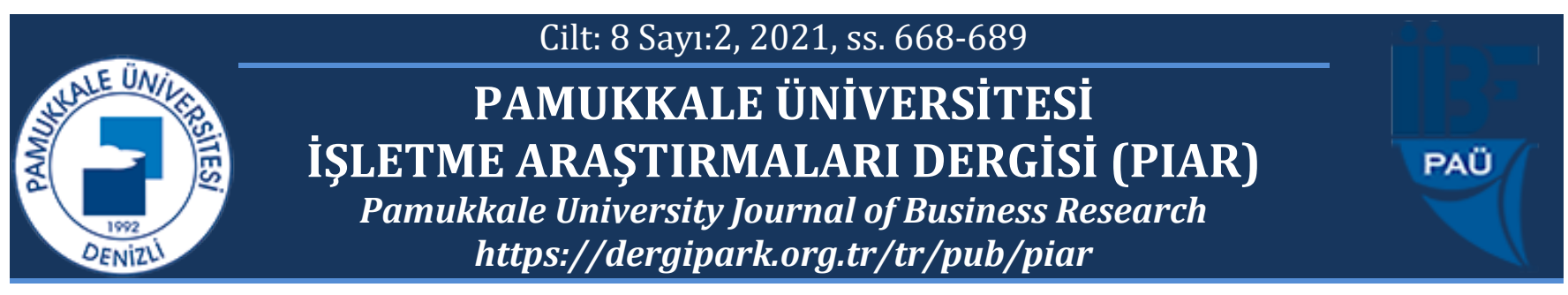

\title{
İstasyonsuz Bisiklet Paylaşım Sistemlerinin Yükselişi ve Düşüşü Üzerine
}

\author{
On the Rise and Fall of Dockless Bike Sharing Systems
}

\author{
Ahmet BARDAKCI ${ }^{1}$ \\ Nazan MADAK ${ }^{2 *}$

\begin{abstract}
${ }_{1}^{1}$ Pamukkale Üniversitesi, İşletme Bölümü, abardakci@pau.edu.tr, https//orcid.org/0000-0003-1391-6432
2 Pamukkale Üniversitesi, Uluslararası Ticaret ve Finansman Bölümü, nmadak@pau.edu.tr, https//orcid.org/0000-00031036-8442

* Yazışılan Yazar/Corresponding author
\end{abstract}

Makale Geliş/Received: 19.11.2021

Makale Kabul/Accepted: 27.12.2021

Öz

Tüketicilerin mal ve hizmetlere geçici olarak erişimine internet tabanlı platformlarla imkân sağlayan paylaşım ekonomisi uygulamaları oldukça yaygınlaşmıştır. 2010'lu yillarda Çin'de icat edilen, herhangi bir istasyona bağhl kalmaksızın kullanılabilir bisiklet paylaşım sistemleri çok kısa bir süre içerisinde uluslararası pazarlara yayılmıştır. Bu harika icat Çin'in dört büyük yeni icadından biri olarak nitelendirilmiştir. Telefona indirilen bir uygulama sayesinde bisikletlerin kilidi açllyyor, yolculuğun bittiği yerde de yine uygulama üzerinden kilitlenip bırakılıyordu. Uygun park yeri arama çabası ve çalınma endişesi elimine edilmişti. Sistem istasyon gerektirmediği için hem yerel idarelerden izin alınması hem de istasyonlar için önemli yatırımlar yapılması gerekmiyordu. İstasyonsuz bisikletler toplu taşıma noktasından sonraki mesafelerde ulaşım sorununa pratik bir çözüm getirdikleri için, aslında çŏ̆u metropolün en büyük ulaşım sorununu çözüme kavuşturmuşlardr.

Ancak bu harika fikrin uygulaması sıkıntısız değildi. Üzerinde düşünülmesi gereken ciddi problemler vardi. Bisikletler özensiz park ediliyordu. Vandallara karşı bir koruma sağlanmamıştı, tahrip edilen bisikletlerin toplanması ve tamir edilmesi gerekiyordu. Pazara girişin kolaylı̆̆ı, aşırı sayıda bisiklete neden olmuştu, firma hakkında duyulan en küçük olumsuzluk kullanıcıların bir anda üyelik iptali ve depozitoları geri istenmesine yol açıyordu. Marka sadakati oluşturabilecek bir farklılı ortaya konulamamıştı ve ikame ürün fazlaydı. Olumsuz yönler ă̆ır bastı bisikletleri çalışır halde tutabilmek, vandallikla mücadele edebilme, kullanıcıların duyarlı park etmemesi gibi nedenlerle birkaç yıl içinde dünyanın en büyüğ̈̈ haline gelen Ofo ve Mobike pazardan çekilmek zorunda kalmıştır.

Haberlerden hareketle istasyonsuz bisiklet paylaşımının serencamın ele alan bu çalışmanın amacı, paylaşım ekonomisi kapsamında ortaya çıkabilecek girişimler için bir vaka çalışması ortaya koymaktır.

Anahtar kelimeler: paylaşım ekonomisi, istasyonsuz bisiklet paylaşımı, Ofo, Mobike

JEL kodlarn: M16, R11, 053, R41, R53

\section{Abstract}

The sharing economy, which allows consumers to temporarily access goods and services through internetbased platforms, has become widespread. Invented in China in 2010s, dockless bike sharing systems quickly spread to international markets. The dockless bike sharing innovation has been described as one of China's four great new inventions. Using an app, bikes are unlocked, and when the journey ends, they are parked then locked via the app. The effort to look for a convenient parking space and the worry of being stolen are eliminated. Since the entire system do not need a dock, any permission from city administration is not needed. In addition, dockless systems are cheaper than station based systems since investments are not required to establish and operate a station. Dockless bikes solve the biggest transportation problem of most metropolises, as they provide a practical solution from public transport to final departures. However, this great idea is not without problems in execution but there are some serious problems to consider. In practice, bicycles were not parked precisely. There was no protection against vandals, destroyed bikes had to be collected and repaired. The ease of entry to the market caused an excessive number of bicycles, the slightest negativity heard about the company caused the users to cancel the membership and demand their deposit back. There is no way to differentiate brands that could create brand loyalty, and there were too many substitutes. The negative aspects outweighed the fact that Ofo and Mobike, which became the biggest in the world in a few years, had to withdraw. Based on the news, this study, which deals with the venture of dockless bike sharing, aiming to present a case for the initiatives that may launch within the scope of the sharing economy.

Keywords: sharing economy, dockless bike sharing, Ofo, Mobike

JEL codes: M16, R11, 053, R41, R53 


\section{GİRIŞ}

Paylaşım ekonomisinin günümüzdeki büyüklügüu Google sonuçlarına göre 2017'de 18,6 milyar US\$ idi (Rendaje, 2021). Akıllı telefonların yaygınlaşması, uygulamaların gelişimi, online ödeme yöntemlerindeki ilerlemeler, bluetooth, GPS ve GPRS teknolojileri bir araya getirilerek ortaya çıarılan paylaşım ekonomileri sistemlerine her gün yenileri eklenmektedir. 2014'te kurulan Ofo ve 2015'te kurulan Mobike, istasyonsuz bisiklet paylaşım sistemleri kuruluşlarından çok kısa bir süre sonra çok sayıda ülkede inanılması güç büyüklüklere ulaşmışlardır. Ancak hızlı yükselişleri kısa bir süre sonra durmuş ve hızla pazardan yok olmuşlardır, aynı saman alevi gibi.

$\mathrm{Bu}$ çalışmada kısaca paylaşım ekonomisi kavramı ele alındıktan sonra bisiklet paylaşım sistemlerine değinilecektir. Dördüncü nesil paylaşım sistemlerinin kâşifi ve en büyük firmalarının Çin, ABD ve Avrupa'daki hayatları gazete ve internet haberleri kapsamında ortaya konulmaya çalışılmıştır. Çalışmanın amacı, ülkemizde Google taramasının gösterdiğine göre hiç çalışılmamış olan istasyonsuz bisiklet paylaşım sistemlerinin handikaplarını ortaya koyarak, bu kapsamda gerçekleştirilecek başta paylaşım sistemleri olmak üzere ve yüksek teknolojiye dayalı mal ve hizmetlerin karşılaşabilecekleri halleri, önceki örneklerinden hareketle ortaya koyabilmektir.

Araştırmanın yöntemi, keşfedici araştırma türlerinden birisi olan vaka analizidir. İlgilenilen konu hakkında bilgi sınırlı olduğu durumlarda, tanımlayıcı araştırmaya temel olması için yapılan keşfedici araştırmaların kat'i sonuçlar ortaya koyamadıkları bilinmektedir (Saunders, Lewis, \& Thornhill, 2012). Çoğunlukla kalitatif olan vaka analizleri için birincil ve/veya ikincil kaynak veriler, geniş bir yelpazede araştırma metodu veya tekniğini ile analiz edilebilirler (Kohlbacher, 2005). Araştırmanın muhteviyatının tek bir vakaya dayanmak zorunda olmadığına dair de görüş birliği bulunmaktadır.

\section{PAYLAŞIM EKONOMISII KAVRAMI ÜZERINE}

Paylaşım ekonomisi kavramı için oldukça fazla sayıda tanım yapılmış olsa da, genel kabul görmüş bir tanım bulunmamaktadır (Kim \& Cho, 2018). Mi \& Coffman, (2019) paylaşım ekonomisini, mal ve hizmetlere erişimin genellikle topluluk tabanlı bir çevrimiçi platform sayesinde bireyler arası paylaşımı şeklinde tanımlamıştır. Marangoz, Bayrakdaroğlu \& Aydın (2017) paylaşım ekonomisi platformları sayesinde, mal ve hizmet için ihtiyacı olanlar ile ihtiyacından fazlasına sahip olan bireyler bir başka aracıya gereksinim duymadan buluşabilmişlerdir. Paylaşım ekonomisi Zipcar, BlaBlaCar, Airbnb vb. hizmet sektörlerini kapsayabileceği gibi, kullanılmış ürünlerin bedelli veya bedelsiz değişimine imkân veren pazarları da içermektedir diyerek paylaşım ekonomisinin bireyler arasında olacağına işaret etmişlerdir. Paylaşımın bireyler arasında gerçekleşeceğini benimseyenler arasında Mair \& Reischauer (2017)'da bulunmaktadır. Bunlar paylaşım ekonomisini, bir kuruluşun işlettiği dijital bir platform aracılığıyla, kaynakların yeniden dağıtımını ve bireylerin kaynaklara erişimini gerçekleştirmek üzere, bireylerin çeşitli olumlu yönlerin değişik şekillerini kullandığ pazar ağ1 olarak tanımlamıştır. Paylaşım ekonomisi kavramında birey yerine firmanın da olabileceğini ifade edenlerden Belk'e (2014) göre; paylaşım ekonomisi kapsamındaki firmalar, tüketicilere geleneksel mülkiyet piyasası modelinde sunulanlardan farklı değer önermeleri sunmaktadır. Paylaşım ekonomisinde, tüketiciler mal ve hizmetlere yalnızca 
geçici olarak erişmektedir ve erişim büyük ölçüde internet tabanlı platformlarla sağlanmaktadır.

Paylaşım ekonomisine değişimin tarafları açısından yaklaşmayan Yu ve Shang, (2017) paylaşım ekonomisinin özünde kaynak kullanımının verimliliğini artırmak, enerji tasarrufu sağlamak ve ekonominin sürdürülebilirliğini gerçekleştirmek için âtıl kaynakların yeniden dağıtımının hedeflediğini belirtmiştir. Âtıl kaynakların kullanılması maliyetleri düşürerek bir tasarruf oluşturacaktır. Kavrama bu şekilde yaklaşan Bocker \& Meelen, (2017) ve Ma et al., (2018) paylaşım ekonomisi platformlarının, kaynak verimliliğini arttırmak ve yeni işler ortaya çıkarmak potansiyelleri sayesinde günlük yaşamda köklü değişimlere yol açabildiklerini belirtmişlerdir.

Paylaşımın coğrafi sınırlarının genişlemesi ve çok sayıda birey arasında iletişimi bağlantıları kolaylaşması elbette internetin gelişimi ve evrimi sayesinde olmuştur. Fotoğraf makinesi ile bütünleşmiş cep telefonunda İnternet'in kullanılabilmesi sonucunda paylaşım ekonomisi gündelik hayatın birçok alanına nüfuz ederek, günlük hayatımızın birçok yönünün değişimine yol açmıştır (Belk 2014). Bireyler eski eşyalarını Letgo; eski giysilerini Dolap, arabasındaki boş koltuğu Bla-Bla-Car ve evlerindeki boş odaları AirBnB gibi uygulamalarla rahatlıkla paylaşabilmektedir. Statista (2020) 2014 yılında dünya genelinde değeri 15 milyar \$ olarak ölçülen paylaşım ekonomisinin 2025 yılında 335 milyar dolarlık bir büyüklüğe ulaşacağını öngörmektedir.

Paylaşım ekonomisi uygulamaları arasında en popüler olan bisiklet paylaşımıdır. Bisiklet paylaşım sistemleri, artan karbon emisyonları, trafik sıkışıklığı ve yenilenemeyen kaynakların kullanımı ile ilgili endişeleri hafifleterek, kişisel otomobil kullanımına karşı cazip alternatifler olarak anılmıştır (Supriyo 2017). Bisiklet kullanımı, binicisine hızlı hareket imkânı sunarken, daha sağlıklı bir yaşam ve daha yeşil ortamlar vaat etmektedir. Kısa mesafeli ulaşım için uygun olan bisiklet paylaşımı dünya çok sayıda kullanıcıyı kendine çekmiştir (Cohen ve Kietzmann, 2014; Manzi ve Saibene, 2017). Kasım 2017 itibariyle, tüm dünyada 1.488 'den fazla şehirde 18.740 .100 'den fazla bisikleti kullanmak üzere kayıtlı yaklaşık 227.000.000 kullanıcı bulunmaktaydı (Zhou ve Zhang, 2019). Bisiklet paylaşım sistemleri, bisiklete sahip olmak ile ilişkili bir maliyet veya bir sorumluluk olmaksızın, bireylere bisikletlere erişimde kolaylık ve esneklik sağlamaktadır (Faghih-Imani \& Eluru, 2016). Paylaşılan bisikletler gerektiği kadar kullanılır, birey bisikleti kullanma kararlarını kısa bir zaman diliminde verilebilir; bu nedenle paylaşımlı bisikletler özellikle kısa mesafeli veya tek yönlü yolculuklar için uygundur (Zhao, Wang ve Deng, 2015; Chen, van Lierop ve Ettema, 2020).

$\mathrm{Bu}$ çalışma kapsamında incelenecek olan istasyonsuz bisiklet paylaşım sistemleri Belk'in (2014) yukarıda verilen paylaşım ekonomisi tanımı ile birebir örtüşmektedir. Paylaşım ekonomisine dayalı ulaştırma sistemleri bize göre; metro, tramvay, otobüs, dolmuş, taksi vb. türden toplu taşıma araçlarını da kapsamaktadır. Ancak çalışmamızın temel amacı, paylaşım ekonomisi olmadığından, bu tartışmaya girilmeyecek, çalışmaya bisiklet paylaşımı sistemleri ile devam edilecektir. 


\section{BİSIKKLET PAYLAŞIM SİSTEMLERİ}

Literatürde bisiklet paylaşım sistemlerinin evrimi dört nesil olarak ele alınmaktadır (örn. Zhao, Zhang, Banks ve Xiong, 2018). Birinci nesil bisiklet paylaşımı 1965 yılında Witte Fietsen-Beyaz Bisiklet- adıyla Amsterdam'da kullanılmıştır (DeMaio, 2009, Davis, 2014). Uygulama Amsterdamlıların ücretsiz kullanımı için sokaklara bırakılmış beyaz bisikletleri kapsamaktaydı. Halk sokaklarda bulunan beyaz bisikletlerle istediği yere gidip, gittiği yerde bisikleti sokaklara bırakıyordu. Ne hırsızlığa ne de vandalizme karşı bir önlem alınmıştı. Bisikletlerin çalınması, kanallara atılması veya kişisel kullanım için özel mülklerde alıkonulmasına bağlı olarak Witte Fietsen uygulaması hızlı bir şekilde yok oldu (DeMaio, 2009). Amsterdam'da başarısız olan birinci nesil bisiklet paylaşımının son derece benzeri bir paylaşım sistemi, Mumbai, Hindistan'da Dabbawala'lar (sefer tası taşıyıcıları) tarafından 1890 yılından bu yana başarıyla kullanılmaktadır. Dabdawalalara ait bisikletler, Mumbai tren istasyonlarında herhangi bir şekilde kilitlenmeden durmaktadır. Dabbawala'lar bu bisikletleri serbestçe kullanıp işleri bittiğinde bisikletleri aldıkları yere bırakmaktadır (örn. Velocitta; 2021). Ancak bu paylaşım ilgili literatürde bizim görebildiğimiz kadarıyla hiç yer almamıştır.

İkinci nesil bisiklet paylaşım sistemleri, günümüzde süpermarketlerdeki alışveriş arabaları veya havaalanlarındaki taşıma arabaları için kullanılan sisteme benzer bir sistemdir. İstasyonlarda bulunan bisikletleri almak için madeni para kullanılıyor, bisiklet istasyona geri getirildiğinde atılan madeni para geri alınıyordu. 1991'de Danimarka'nın Farso ve Grena, 1993'te Nakskov şehirlerinde (Nielsen, 1993) ve büyük bir ölçekle 1995'te Kopenhag'da Bycyklen veya City Bikes adıyla kullanılmaya başlanmıştır. Madeni parayı atarak bisikleti istasyondan alan kişinin kimliğinin bilinmemesi, bu neslin hırsızlık açısından en önemli açı̆̆ını oluşturmaktaydı (DeMaio, 2009).

Üçüncü nesil bisiklet paylaşım sistemlerinde bisikletler istasyondan kredi kartı kullanılarak alınabilmekte, bisiklet istasyona bırakıldığında ise kullanım süresine tekabül eden ücret, kiralayanın kredi kartından tahsil edilmektedir (Shaheen ve diğ., 2013). Midgley, (2011) ve Shaheen ve diğerleri (2010) belirttiğine göre; üçüncü nesil bisiklet paylaşım sistemi, gelişmiş bisiklet tasarımları, sofistike istasyonlar, kredi kartı, akıllı kart kullanımı ve bisikleti istasyona elektronik olarak kilitleme özellikleri ile önceki nesilden ayrılmaktadır. Bu nesil sistem ilk olarak 1998'de Rennes'de (Shaheen ve diğerleri, 2010; Midgley, 2011) 2000'de Münih'de, 2005'te 1.500 bisikletle Lyon'da hizmete açılmıştır 2007'de Paris'de yaklaşık 7.000 bisikletle kullanıma alınan Velib programı ile Paris ve banliyölerinde üçüncü nesil paylaşılan bisiklet sayısı 23.600'e yükselmiştir. Paris'te elde edilen bu başarı bisiklet paylaşım sistemleri tarihinin akışını değiştirmiştir ve üçüncü nesil sistemler dünyanın dört bir yanına sıçramıştır. 2008'de Brezilya, Şili, Çin, Yeni Zelanda, Güney Kore, Tayvan ve ABD'de bu nesil bisiklet paylaşımları kullanılmaya başlamıştır (Pucher \& Buehler, 2008; DeMaio, 2009). Kuzey Amerika'daki en büyük bisiklet paylaşım sistemi ise New York'ta 2013'te on bin bisikletle kullanıma alınmıştır (Kim, \& Cho, 2018).

Pekin'de üniversite öğrencisi Dai Wei'nin, beşinci bisikleti çalındıktan kısa bir süre sonra, Pekin Üniversitesi'ndeki başka bir öğrenci tarafından ikinci el olarak satın alınıp kullandığını fark etmesi dördüncü nesil bisiklet paylaşımının doğuşuna yol açmıştır. Dai Wei, bu icadını aslında ile Çin'deki yaygın olan bisiklet hırsızlığına karşı bir çözüm olarak geliştirmiştir. 
İnsanların bisiklet sahibi olmaları gerekmiyordu, ihtiyaçları olduğu yerde bisikleti kiralayıp, işlerinin bittiği noktada bisikleti bırakacaklardı. Bu tür bir kiralamada bireyler bisikletlerinin çalınması endişesi taşımayacaklarından, kiralamak; sahip olmaktan daha avantajlı olacaktı. Dördüncü nesil bisiklet paylaşım sistemlerinde, ikinci ve üçüncü nesilde olduğu gibi, bisikletlerin alınıp bırakılabileceği bir istasyon bulunmamaktadır. Akıllı bisiklet paylaşımı olarak da anılan bu sistem ilk olarak Pekin'de 2014'te Dai Wei tarafından kurulan Ofo, ve 2015'de Mobike firmaları tarafından kullanılmaya başlamıştır (örn. Zhao, Zhang, Banks ve Xiong, 2018). Bu metinde bu noktadan sonra istasyonsuz bisiklet paylaşım sistemleri olarak nitelendireceğimiz dördüncü nesil sistemler, üçüncü nesilde var olan istasyona erişim kolaylığı, istasyonlardaki sınırlı park yerleri ve yerel yönetimlerin büyük desteğine duyulan ihtiyacı ortadan kaldırmıştır. Dördüncü nesil bisiklet paylaşım sistemi, bir uygulamaya, bisiklete yerleştirilmiş bir GPS cihazına, bisikletlerin yerlerini tespit etmek ve akıllı kilidi açmak için internet bağlantısına ihtiyaç duymaktadır (Chen, van Lierop ve Ettema, 2020). Bu kapsamda bu nesil bisikletler GPS, GPRS, Bluetooth ve QR Kodu teknolojileri ile mobil ödeme yöntemleri teknolojilerini bütünleştirmiştir (Zhao, Zhang, Banks ve Xiong, 2018). Bisiklet üzerinde var olan teknoloji ise gücünü genellikle bisikletin tekerlek göbeğine yerleştirilmiş olan dinamonun şarj ettiği bir pilden sağlamaktadır (Belton, 2018).

\subsection{Dördüncü Nesil Bisiklet Paylaşım Sistemlerinin Yükselişi}

İstasyonuz bisiklet paylaşımı fikrinin kâşifi Dai Wei'nin kurduğu paylaşım şirketi Ofo, kuruluşundan sadece üç yıl sonra 21 ülkede 250'den fazla şehirde faaliyet gösteren 2 milyar dolarlık bir işletmeye dönüşmüştür. Sayıları 10 milyonu bulan Ofo markalı sarı bisikletlerle her gün 32 milyon defa kullanılmaktaydı. Şirketine gidip gelmek için kendisi de Ofo bisiklet kullanan Dai, Sarı bisikletlerimizi Starbucks veya McDonald's kadar yayginlaştırmak istiyoruz diyerek şirketinin hedefini açıklamıştı (Campbell, 2018). 2018 yılında Çin'deki en büyük iki operatör olan Ofo ve Mobike dahil, tüm dünyada 70 kadar istasyonsuz bisiklet paylaşım firmasının yaklaşık 16 milyon bisiklete sahip olduğu ve bunların günde 50 milyondan fazla kullanıldığı belirtilmiştir (Zhao, Zhang, Banks ve Xiong, 2018). İstasyonsuz paylaşım o kadar popüler hale gelmişti ki farklı aylarda yayınlanan makalelerde bisiklet sayıları hızla yükselmiştir. Örneğin, Re (2018) sadece Ofo ve Mobike'a ait 17 milyondan fazla bisiklet bulunduğunu yazmıştır. Mobike CEO'su Davis Wang'da sadece Pekin'de turuncu Mobike bisikletlerinin günde 4 milyon kez kullanıldığını belirtmiş̧tir. Campbell, (2018) sadece Çin'deki caddelerine 60 civarında firmanın 16 ile 18 milyon adet bisiklet bıraktığını belirtirken, Çin için en yüksek rakam 77 bisiklet paylaşım şirketine ait 23 milyon bisikletin Çin sokaklarında olduğu şeklinde haber yapan ECNS Wire (2018) sitesine aittir. İstasyonsuz bisikletin icat edildiği Çin'de, paylaşım bisikletleri metro ve otobüslerden sonra üçüncü büyük toplu taşıma türü haline gelmiştir. Çin'in iki büyük bisiklet paylaşım şirketi olan Mobike ve Ofo, Çin'de 170'ten fazla şehirde rekabet etmekteydi (Tan ve Dafei, 2018). 


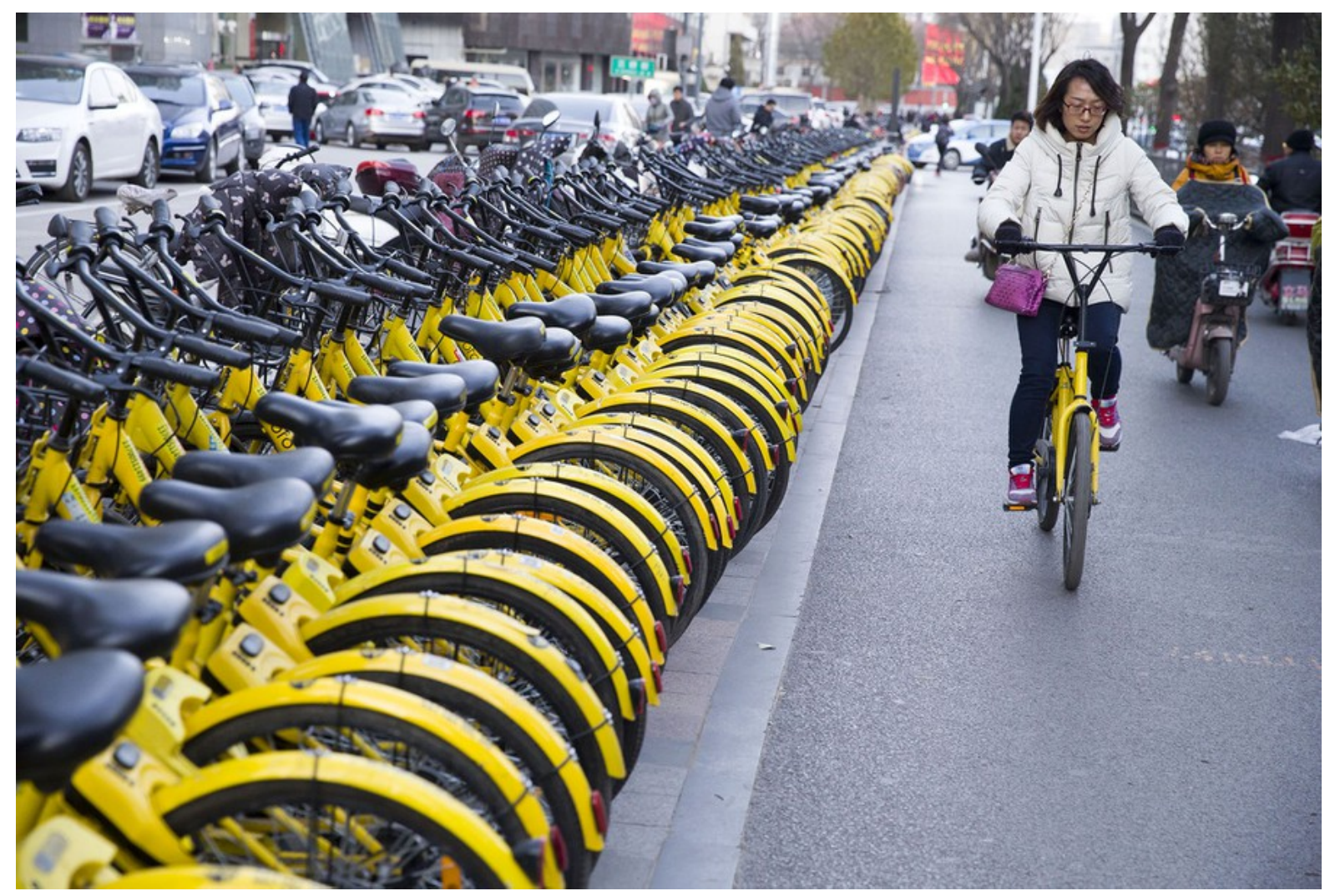

Fotoğraf 1: Pekin'de Ofo bisikletleri sıralanmış kullanıcılarını bekliyor, 23 Kasım 2017 (Taylor, 2018).

Belton (2018) dünya genelinde 18 milyon dördüncü nesil bisiklet olduğunu yazmıştır. Campbell'in (2018) belirttiğine göre 2018'de Pekin'de 2,4 milyon dördüncü nesil paylaşılabilir bisiklet ve 11 milyon kayıtlı kullanıcı bulunuyordu. Aynı tarihlerde ABD'de büyük bisiklet paylaşım şirketi ise üçüncü nesil bisiklet paylaşımı yapan on bin bisikleti ve 236.000 kullanıcısı bulunan New York City'deki Citi Bike idi. Yine aynı yıllarda Paris'te 21.000; Londra 16.500 civarında paylaşım bisikleti bulunmaktaydı. 2016 yılında çoğunluğu Çin'de olmak üzere, 1.000 (Shaheen ve Chan, 2016) 2018 yılında ise 1.608 (Belton, 2018) şehirde istasyonsuz bisiklet paylaşım sisteminin kullanıldığı belirtilmiştir. Berlin sokakları da baş döndürücü istasyonsuz bisiklet yayılımından nasibini almıştır, Dobush'un belirttiğine göre (2018) Berlin sokaklarına 2.000'i Ofo'ya ait 18.000'den fazla bisiklet işleten sekiz firma faaliyet gösteriyordu.

İstasyonsuz bisiklet paylaşım sistemleri, bireysel kullanıcılara önemli avantajlar sağlamaktadır. Telefona indirilen uygulama kullanılarak yapılan ilk kayıt işlemi nispeten basittir. Sisteme giriş yapan kullanıcılar akıllı telefonları ile kolaylıkla bisikletlerin kilidini açabilir. Bisiklet kullanımı bir istasyonla sınırlı olmadığından, istasyon tabanlı sistemlere kıyasla daha esnektirler daha geniş bir hareket alanına sahiptirler. İstasyon kurulum maliyeti olmadığından, nispeten düşük ilk yatırım maliyetlerine bağlı olarak kullanım ücretleri önceki nesil sistemlerden daha düşüktür (Re, 2018; Belton, 2018; Keown, 2018). Örneğin Londra'da, 25 bisiklet kapasiteli tipik bir istasyonun kurulum ve yıllık bakım maliyeti yaklaşık 100.000£ GB'dir. İstasyonsuz sistemlerde bu maliyet ölçek ekonomilerine ulaşan firmalar için 2500 US\$ civarına düşmektedir (Belton, 2018). Bir istasyonun olmaması yerel 
yönetimlerden altyapı için izin alınmasını gerektirmemektedir. İstasyon altyapısının olmayışı yatırım maliyetlerini düşürmek yanında firmaların pazara girişlerinin olağanüstü şekilde kolaylaştırmıştır (Griffith, 2018).

İstasyonsuz bisiklet paylaşım sisteminde bisikletlerin konumunu, bir önceki kullanıcı belirlediğinden bir bisiklete erişim için potansiyel kullanıcıların yollarını değiştirmesi gerekebilir. Ancak bu yolculuk bir istasyonda bitmeyeceği için varış noktasında ilave bir yürüyüş gerektirmez. İstasyonsuz bisiklet paylaşımı sistemleri, konumlanmak için istasyon ihtiyacı duymayacağından, şehirdeki toplu taşıma sistemi ile bütünleşmesinin çok daha kolay olacağı düşünülmektedir (Chen, van Lierop ve Ettema, 2020). Toplu taşıma istasyonlarında istasyonsuz paylaşım bisikletlerine erişim sağlayabilmek için büyük bir bisiklet filosuna duyulan ihtiyaç yanında, bu bisikletleri en çok ihtiyaç duyulan zamanda uygun alanlarda hazır bulundurabilmek için iş gücüne gereksinim duyulabilir. Zira bu nesil bisikletler kullanıcıların yolculuklarına başlaması için ideal noktalara bırakılmazlar. Bu açıdan bakıldığında istasyonsuz bisiklet çözümü Çin'e oldukça uygun gözükmektedir zira, işgücü ucuzdur ve bisiklete binmeyi seven kalabalık bir kentsel nüfus vardır. Çin'de nüfusu 1 milyonun üzerinde yüz şehir vardır ve 2025'e kadar bu sayının 221'e yükselmesi beklenmektedir (Shead, 2017; Belton, 2018).

Çin'deki devasa pazar potansiyeline paralel olarak dördüncü nesil istasyonsuz bisiklet paylaşımında asıl rekabet Çin'li Alibaba gibi devasa grupların desteğini alan Ofo ile Mobike'ın hakimiyet için mücadele ettiği Çin'de yaşanmıştır (Belton, 2018). Çin akıllı bisikletler krallığı olmak için çok hızlı şekilde yol almıştır (Zhao, Zhang, Banks ve Xiong, 2018). Ancak rekabet sadece Çin'le sınırla kalmamış baş döndürücü bir hızla dünyanın farklı ülkelerine yayılmıştır, Çin Devlet Başkanı Xi Jinping, farklı zamanlarda, gururla istasyonsuz bisiklet paylaşımı devriminin Çin'in dünyaya bir hediyesi olduğunu dile getirmiştir (Campbell, 2018; Chen, van Lierop ve Ettema, 2020). Çin Devlet ajansı Xinhua da bisiklet paylaşımını Çin'in dört büyük yeni icadından biri olarak nitelendirmiştir (Shead, 2017). O tarihlerde Çin'den dünyaya yayılan istasyonsuz bisiklet akımı Govindarajan ve Trimble (2013) tarafından kavramsallaştırılan Ters İnnovasyon kuramı ile de birebir örtüşmektedir.

İstasyonsuz bisikletler toplu taşıma noktasından sonraki mesafelerde ulaşım sorununa pratik bir çözüm getirdikleri için, aslında çoğu metropolün en büyük ulaşım sorununu çözüme kavuşturmuşlardır. Çoğu metropolde her gün milyonlarca insanı şehir merkezlerine taşıyan tren sistemleri halihazırda çalışmaktadır. Ancak şehir merkezlerinde toplu taşıma istasyonu sonrası için yürümek dışında bir seçenek bulunmamaktadır. Shead (2017), metro gibi bir toplu taşıma istasyonu sonrasında 15 dakika kadar yürümek yerine istasyonsuz bisikletlerin inanılmaz kolaylık sağladığını bizzat tecrübe etmiştir. Çin büyük şehirleri bu anlamda Mobike veya Ofo gibi firmalar için mükemmel bir altyapı sunmaktadır (Shead, 2017). Bu noktada yolculuğun sona erdiği yere bırakılabilir nitelikte bir kiralık bisiklete erişimin değeri ortadadır. Bu değer Şanghay'da istasyonsuz bisikletlerin sayısının Şubat-Ağustos 2017 arasındaki altı ayda 450.000'den 1.500 .000 yükselmesini kolaylıkla açıklamaktadır (Salmon, 2018). Bu bağlamda ABD'nin Wilmington şehrinde bisiklet paylaşımının toplu taşıma sisteminin bir tamamlayıcısı olduğu, toplu taşıma aracını beklemek için çok kısa ama yürümek için çok uzak mesafeler için kolay ve erişilebilir bir ulaştırma seçeneği sunduğu belirtilmiştir (Wilmington Bike Share Feasibility Study, 2016). 
Üçüncü nesil istasyonlu bir bisiklet paylaşım sistemine ev sahipliği yapan ilk ABD şehri Washington DC, 2018'de istasyonsuz bisiklet paylaşımı alanında beş şirketin rekabetine sahne olmuştur. ABD geneli ele alındığında 2018 'de dördüncü nesil paylaşım, toplam bisiklet paylaşımının sadece \%13'ü kadar olsa da bu pay hızla artmıştır (Tan ve Dafei, 2018).

\subsection{Dördüncü Nesil Bisiklet Paylaşım Sistemlerinin Düşüşü}

Mobike firması Hong Kong, Singapur ve Çin anakarasındaki büyük başarısının ardından Asya dışındaki ilk lansmanını Haziran 2017'de Manchester, İngiltere' de gerçekleştirmiştir (Pidd 2018). Mobike Manchester pazarına girerken, bisikletlerinin vandalizme dayanıklı oluğunu iddia etmiştir, ancak bu iddia bir grup Salford'lu tarafından bir meydan okuma olarak algılanmıştır. Birkaç hafta sonra, bir grup çocuğun Mobike bisikletini taşlama videosu viral olmuştura, sonrasında Mobike'ların su kanalına atıldığına dair haberler peş peşe medyaya düşmeye başlamıştır (Pidd, 2018). 2017 yılında her ay filosunun neredeyse \%10'u tahrip olan veya çalınan Mobike, Eylül 2018'de Manchester'daki faaliyetlerini sonlandırmıştır. Bu bir Çinli istasyonsuz bisiklet paylaşım firmasının vandallıkla baş edemediği için ilk kez bir şehri terk etmesi anlamına gelmektedir. Mobike'in daha önce Washington DC ve Dallas'tan çekilmesi operasyonel etkinliğin kazanılamamasına bağlanmıştır (Pidd, 2018; Lindsay, 2018; Kollewe ve McIntyre, 2019).

Ofo firması da çok hızlı girdiği İngiltere pazarında 18 aydan daha kısa sürede vandalizmle ilgili ciddi sorunlar yaşadığı için, Norwich, Sheffield ve Oxford pazarlarından çekilmiştir. Ofo, zirvedeyken Londra, Norwich, Sheffield, Oxford ve Cambridge'de yaklaşık 6.000 bisikleti bulunmaktaydı. İngiliz pazarında küçülme sonrası bütün enerjisini Londra'ya harcamaya başlayan Ofo, Ocak 2019'da Londra'dan da çekilmiştir (Kollewe ve McIntyre, 2019; Ffrench 2019).

Vandalizme karşı önlemler de alınmaya çalışılmıştır. Mobike İngiltere'de, Newcastle ve Gateshead'de, Ofo ise Norwich'de belirlenmiş bir alanın (Geofence) dışına çıkışı engellemiştir (Lindsay, 2018; Massey, 2017) ancak Geofence vandallığa karşı bir çözüm olmamıştır. Öte yandan Oxford'da yerel yönetim paylaşım bisikletleri ile ilgili yok denecek kadar az sayıda vandallık yaşandığı belirtilmiştir (Keown, 2018). 2018' de Çin pazarında 77 bisiklet paylaşım şirketinden 20'sinden fazlasının nedenleri belirtilmemiş olsa da operasyonlarını durdurduğu açıklanmıştır (ECNS Wire, 2018).

2014 yılında Pekin'de kurulan Ofo, 2017'de 20 ülkede 250 şehirde 10 milyon bisikleti sokaklara bırakmıştı, aylık 63 milyon kişi tarafından aktif olarak kullanılıyordu ve firmanın değeri ise 2 milyar US\$ civarındaydı. 2018' de ciddi zarar açılayan Ofo, 2020 yılında 4. Nesil istasyonsuz bisiklet paylaşım işinden tamamen çıkmıştır (Ofo, Wikipedia).

Mobike ise 2015 yılında kurulmuş ve rakiplerindan farklı olarak, arzu etiği nitelikte bisiklet bulamadığı için kendi bisiklet tasarımını kendisi yaparak Nisan 2016'da faaliyete başlamıştır. Aralık 2016'da Şangay'ın dünyanın en fazla istasyonsuz paylaşım şehri olmasındaki en önemli aktör olmuştur. Haziran 2017' de Mobike'ın değeri 3 milyar US\$ olarak açıklanmıştır. Nisan 2018' de 2,7 US \$ Çinli internet hizmet sağlayıcı Meituan-Dianping firması tarafından

\footnotetext{
a https://www.manchestereveningnews.co.uk/news/greater-manchester-news/mobike-theft-vandalism-attacksmanchester-13314463
} 
satın alınan Mobike Nisan 2018 itibarıyla 19 ülkede 200 şehirde faaliyet göstermekteydi. Temmuz 2018' de faaliyetlerini durdurmuştur (Mobike, Wikipedia).

\section{4. İSTASYONSUZ BİSIKLET PAYLAŞIM SISTEMLERINININ KARŞILAŞTIĞI ZORLUKLAR}

\subsection{Rastgele park etme davranışı yaygındır}

İstasyonsuz bisiklet paylaşım sistemleri park etmeyi kuralsızlaştırmıştır ve bu kuralsızlık bisikletlerin çoğunlukla düzensiz park edilmesine neden olmuştur. Düzensiz parklar genel olarak kaldırımların ve bisiklet yollarının kullanılamaz hale gelmesi, metro istasyonlarının, ofis bloklarının vb. kapılarında yaya akışının engellenmesi gibi ciddi olumsuzluklara neden olmuştur (Yu ve Shang, 2017; Chang, Song, He \& Qiu, 2018; Shi, Si, Wu, Su ve Lan, 2018). Bu tür olumsuzluklar sadece Çin'de yaşanmamıştır, Avrupa şehirlerinde de bu bisikletler yüzünden tıkanmış kaldırımlar, kırık bisiklet yı̆̆ınları ve hatta otoyollara park edilmiş bisikletlere sıkça rastlanmıştır (Campbell, 2018; Re, 2018). Yerel yönetimlerin, şehirlerine binlerce bisiklet bırakan şirketler üzerinde; şirketlerin de kullanıcılar üzerinde, bisikletlerin nereye bırakılacağı konusundaki kontrolü azaldığında, sonuçlar olumsuz olmuştur. Kuralsızca park edilen bisikletler araç ve yaya trafiğini olumsuz etkilemiş, sahipsiz bisikletler çalınmış ve parçalanmıştır. Bu nedenle Çin şehirleri, istasyonsuz bisikletlerin karmaşası ve dağınıklığı tarafından ele geçirildi denilmiştir (Salmon, 2018).

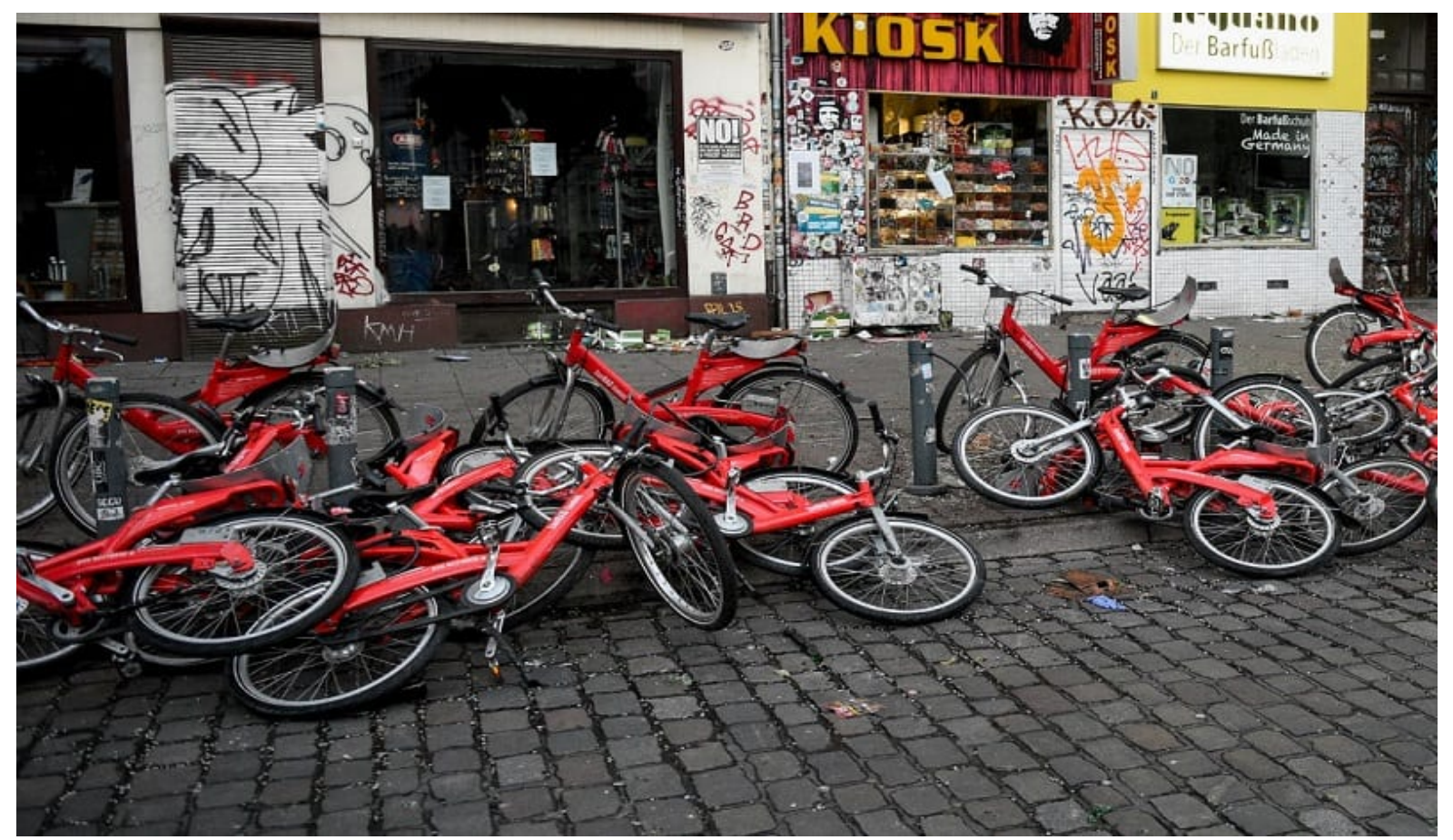

Fotoğraf 2: Rastgele park edilmiş bisikletler, Londra (Talbot, 2019). 


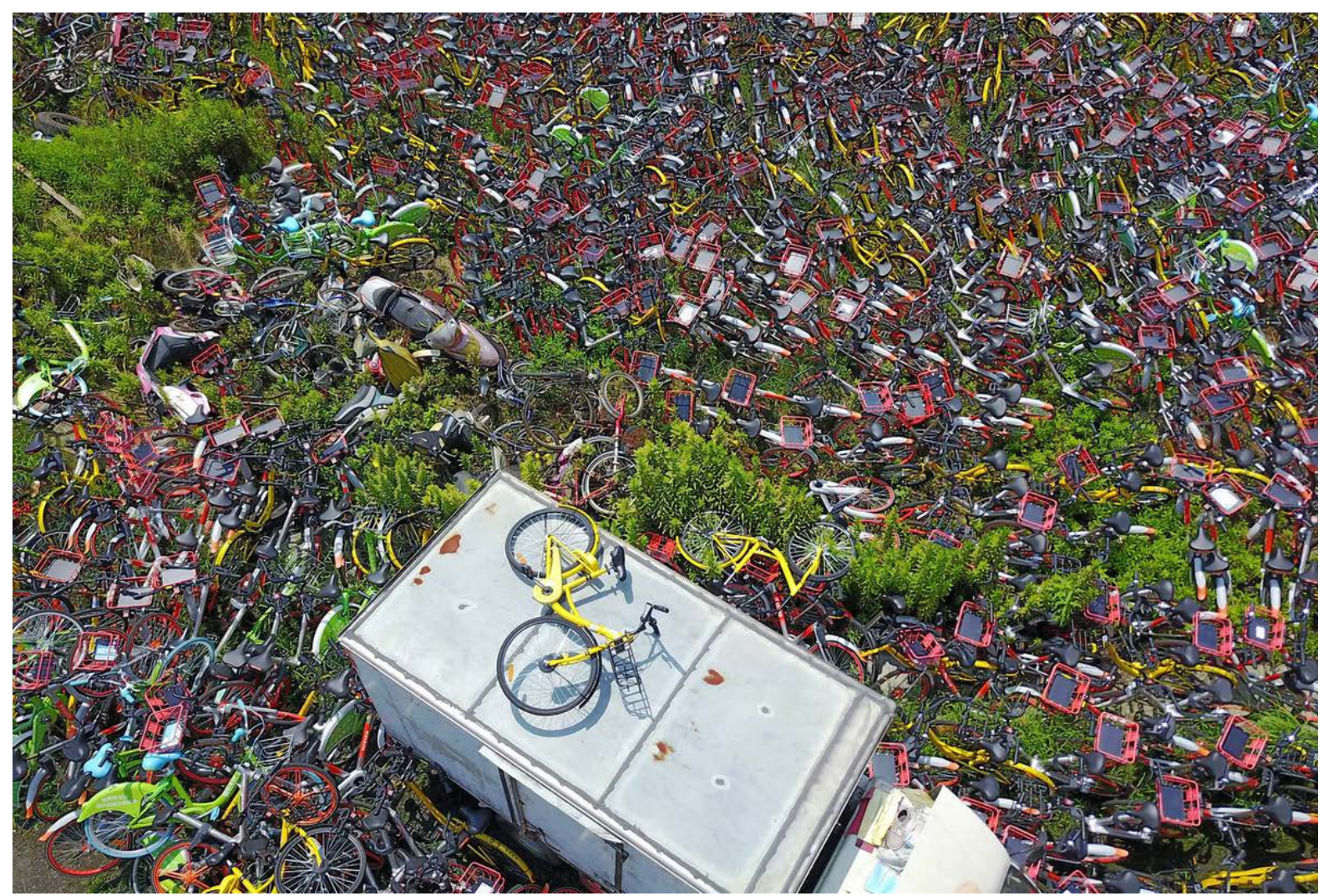

Fotoğraf 3: Hatalı park nedeniyle yerel yönetimlerce geçici olarak el konulan binlerce bisiklet, Hefei, Anhui, Çin. 17 Ağustos 2017 (Taylor, 2018).

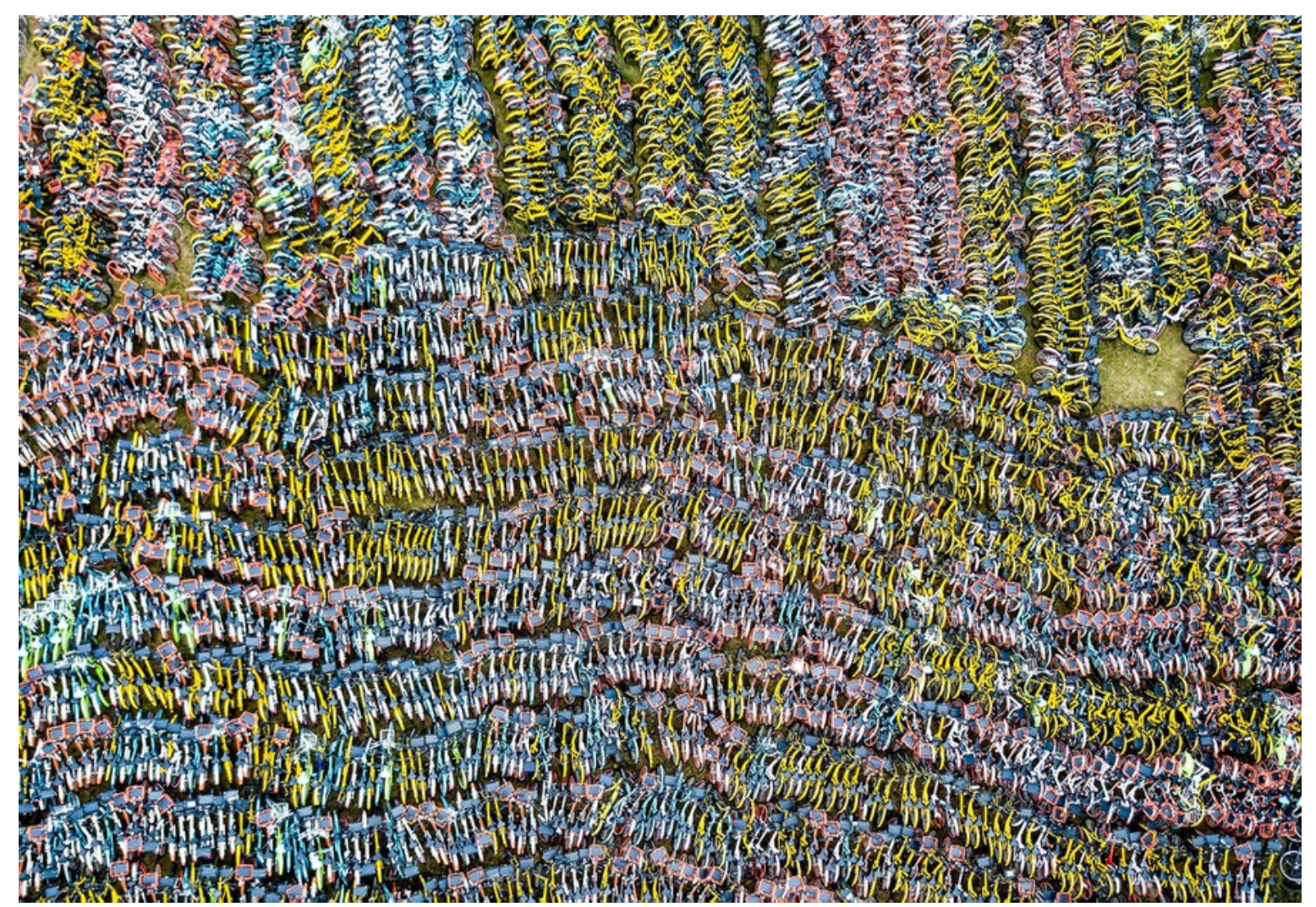

Fotoğraf 4: Sokakları ve kaldırımları işgal ettikleri için polis tarafından toplanıp bir alana 
terk edilmiş paylaşılan bisikletlerin havadan görünümü, 28 Haziran 2017'de, Zhejiang, Hangzhou, Çin (Taylor, 2018).

\subsection{Vandalizm yaygindır}

Sabit bir istasyon altyapısına bağlı olmama avantajı, kullanıcıların bisikletleri bir başka kullanıcının bulunma olasılığı düşük olan noktalara bırakabilmesine imkân sağlamıştır, şehrin varoşlarında bisikletlerin zarar görme riski daha yüksektir (The Conversation, 2019).

Dünyanın her şehrinde çok sayıda istasyonsuz paylaşım bisikletinin QR kodlarının tahrip edildiği için elektronik kilitleri yeni kullanıcılar tarafından açılamamaktadır. Bunun yanı sıra kilit sistemi tamamen tahrip edilmiş ve yerine şahsi bisiklet kilidi takılarak sahiplenilmiş veya kişilerin özel mülkleri içine park edilerek başkalarının kullanımına izin verilmeyerek sahiplenilmiş çok sayıda bisikletin olduğu tespit edilmiştir (Campbell, 2018; Re, 2018). Etrafta koltuğu, pedalları veya tekerlekleri eksik olan istasyonsuz paylaşım bisikletlerini sistemin bulunduğu her şehirde rastlandığı belirtilmiştir. Rakamlar, Guangzhou'daki Mobike'ların \%10'unun bir şekilde sabote edildiğini göstermektedir. Bu kadar yüksek vandalizm oranı, paylaşılan bisikletlerin maliyetlerini büyük ölçüde artırmıştır (Yu ve Shang, 2017). Firmaların vandallık yüzünden kaybettikleri bisiklet sayılarını kontrol altına alabilmek için uygulamaya aldıkları önlem, bisikletlerin bir 'geofence' (sanal bir coğrafi sınır) dışına çıktığında 20 sterlinlik bir para cezasına çarptırılmasını içermektedir (Lindsay, 2018).

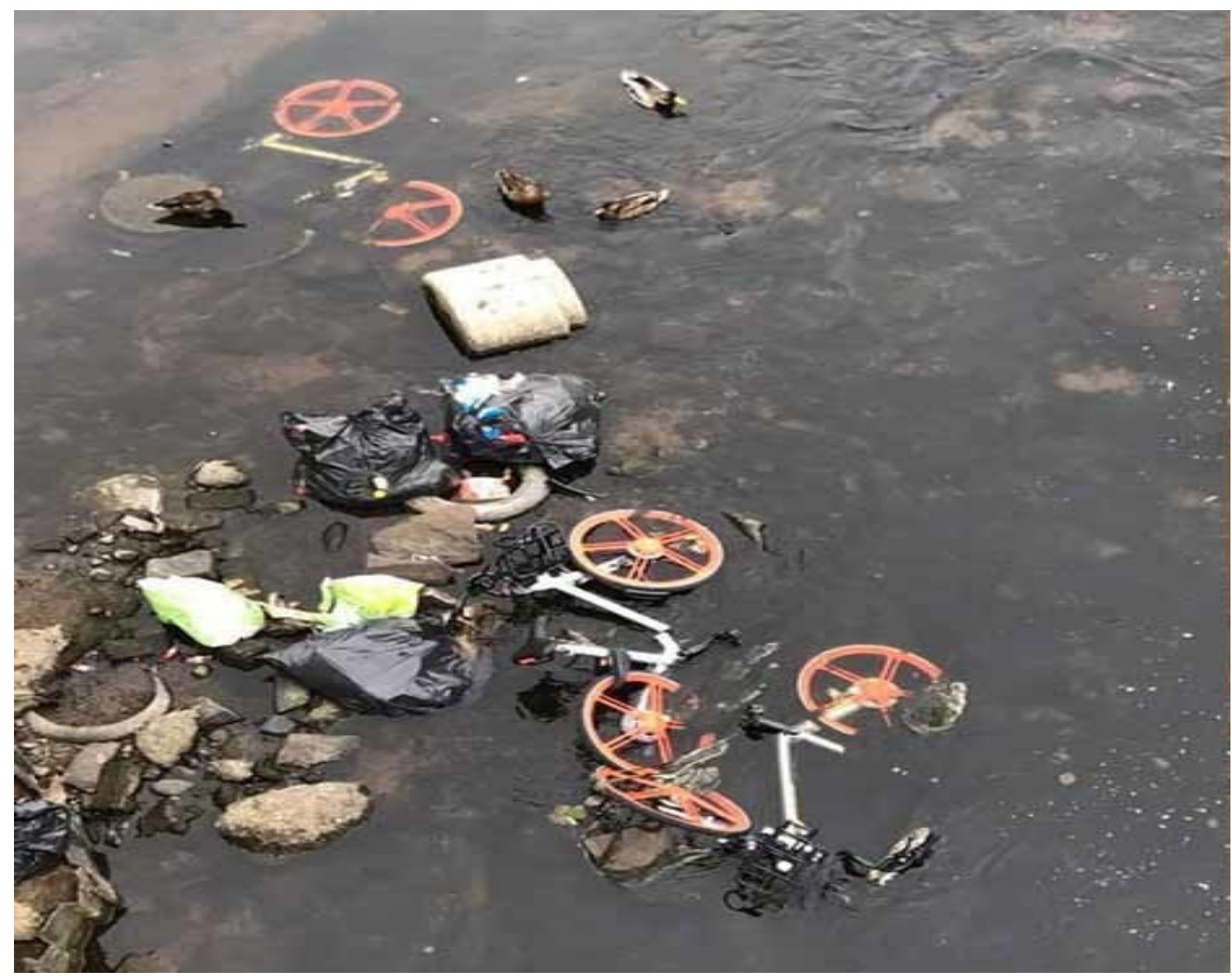

Fotoğraf 5: Salford, Manchester kanala atılmış Mobike'lar, 5 Eylül 2018 (Karl, 2018). 


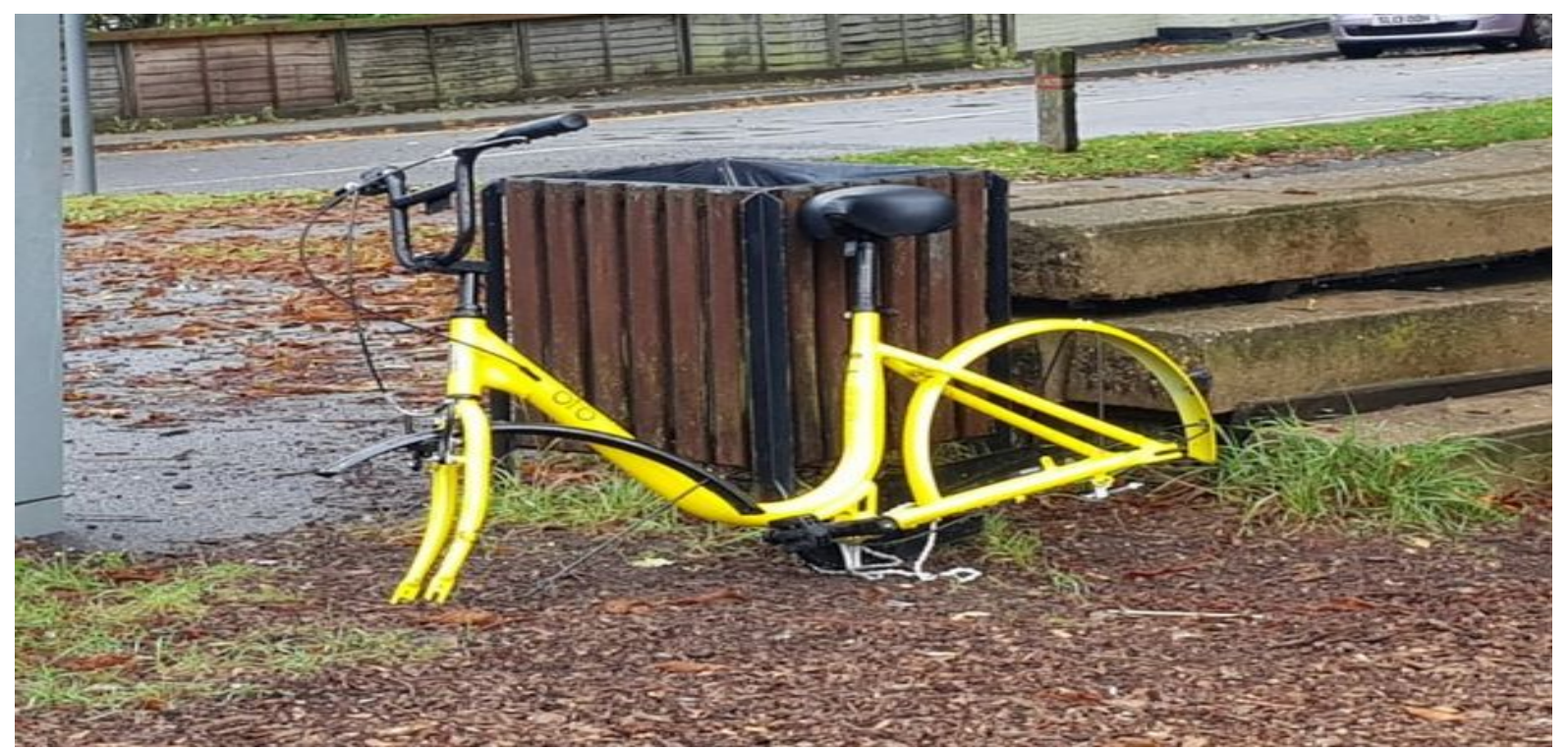

Fotoğraf 6: Tekerlekleri çalınarak terkedilmiş bir Ofo (Brown, 2018).

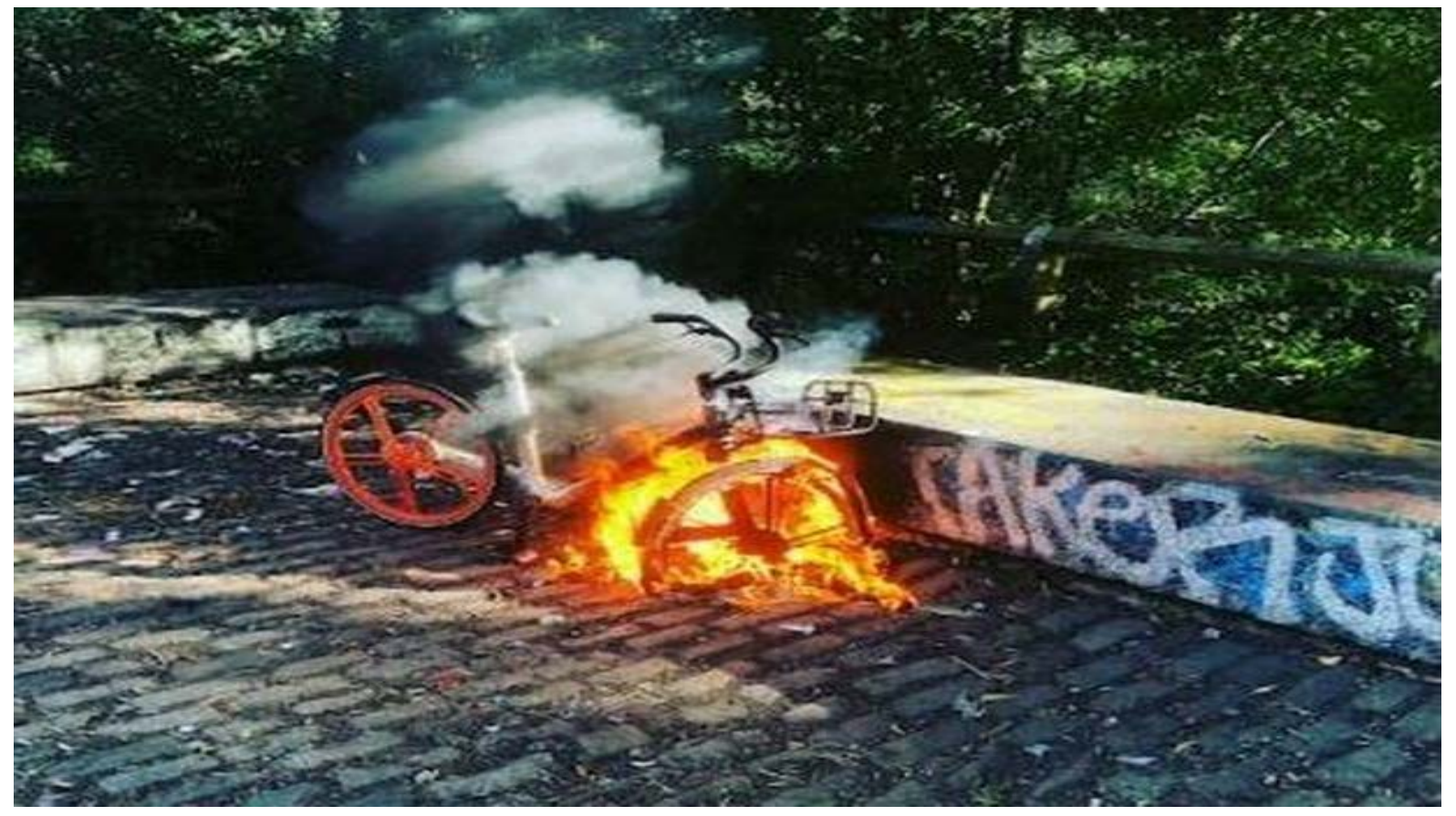

Fotoğraf 7: Ouseburn, Newcastle'da ateşe verilmiş bir Mobike (Johnson, 2018).

Bu kapsamda değinilmesi gereken bir husus da bisikletlerde meydana gelen arızaların bakım ve onarımı ile ilgilidir. Nihayetinde kişinin kendine ait olmayan bir bisiklete yeteri kadar iyi davranmasını beklemenin mümkün olmadığı öğrenilmiştir. Bu bağlamda bisikletler sık sık arızalanmıştır. Zincirin çıkması, frenlerin bakımı ve onarımı, koltuk ayar vidalarının aşırı sıkılmasına bağlı olarak açılamaması gibi çok sayıda arızanın zamanında müdahaleye ihtiyacı olmuştur. Ancak bunlarla ilgili olarak da firmalar yeterince çözüm üretememiştir. Pekin, Chaoyang bölgesi'ndeki bir onarım yerine günde yaklaşık 600 Ofo'nun onarım için gönderildiğini belirtilmiştir (Taylor, 2018). Campbell (2018) arızalı bisikletlerin alandaki 
yaygınlığına örnek olması için Pekin'de binebilir problemsiz bir bisiklet bulabilmek için on problemli bisikletinin denenmesi gerektiğini ifade etmiştir.

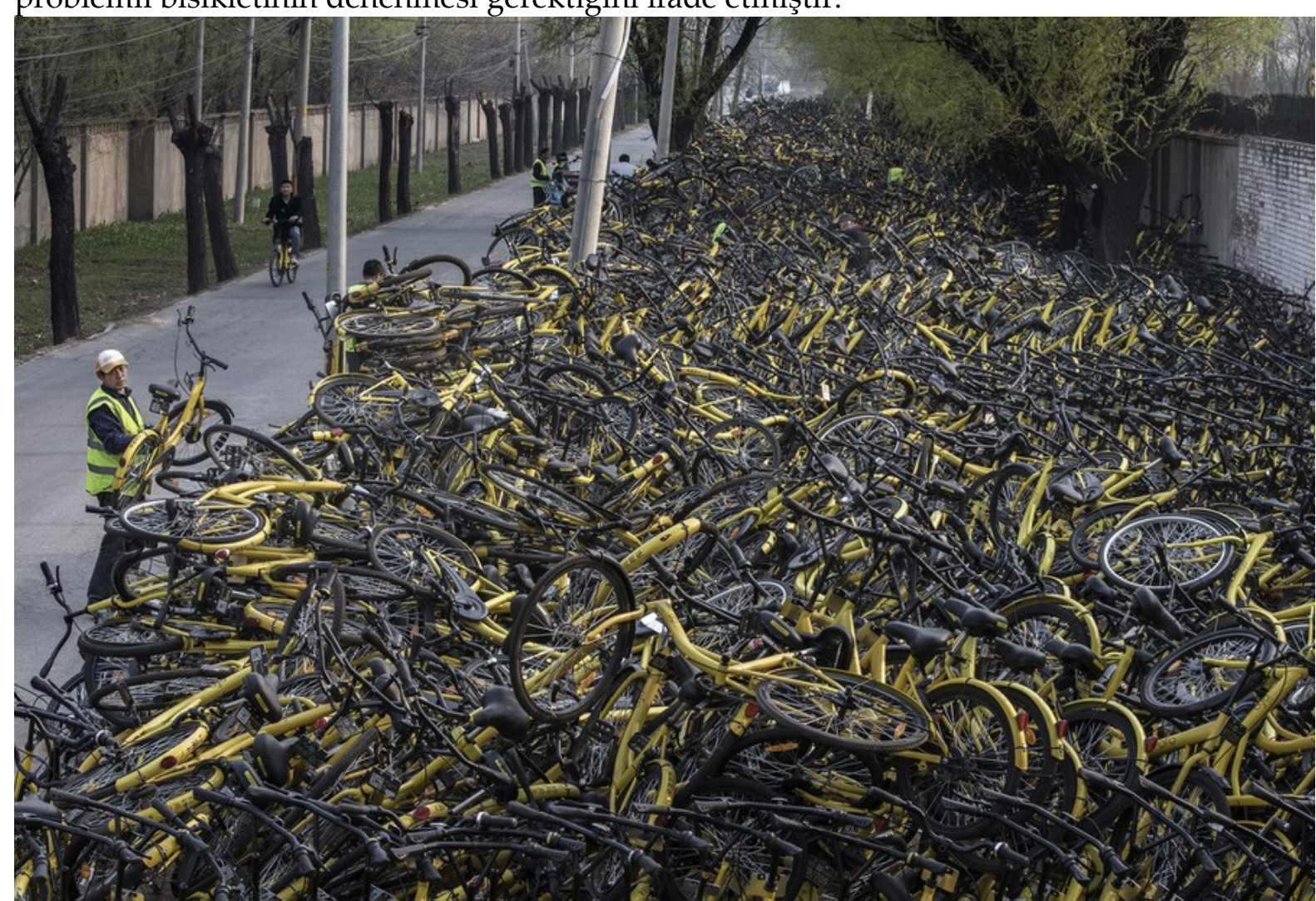

Fotoğraf 8: Ofo tamir bakım servisi çalışanı, hasarlı bir bisikleti tamir atölyesinin deposunun yanındaki bisiklet yığının üzerine yerleştiriyor. Pekin'de arızalı binlerce bisiklet bu depoda tutuluyor. 29 Mart 2017 (Taylor, 2018). 


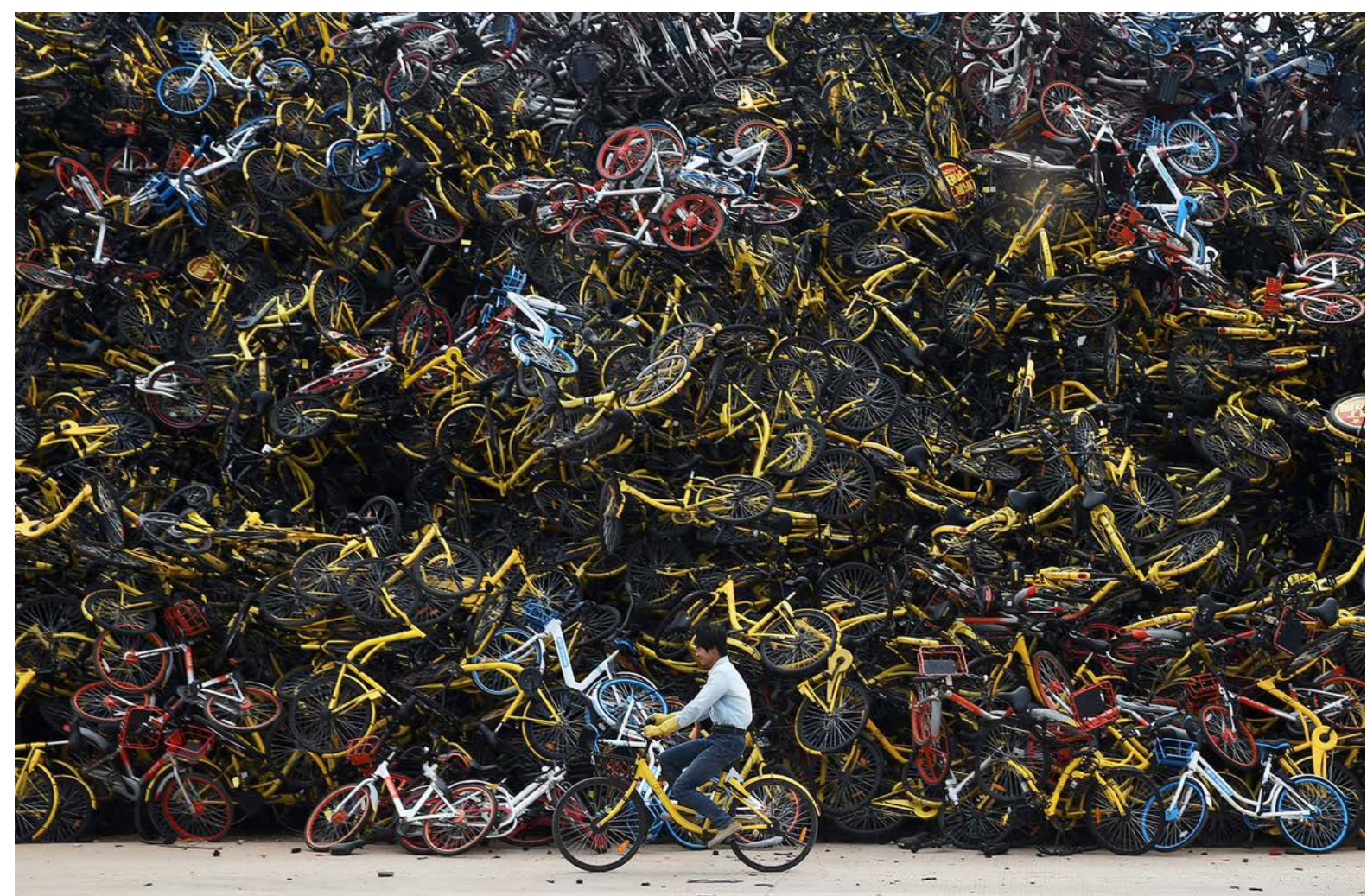

Fotoğraf 9: Kullanılmayan paylaşım bisikletlerinden oluşan büyük bir yığınının yanından paylaşım bisikleti ile geçen bir işçi, Fujian, Xiamen Çin. 13 Aralık 2017 (Taylor, 2018).

\subsection{Bisiklet arzı bisiklet talebinden fazladır}

İstasyonsuz bisiklet paylaşımının bir anda popüler hale gelmesine bağlı olarak çok sayıda yatırımcı konuya ilgi göstermiştir. 2017'lerde Çin'de faaliyet gösteren 30'dan fazla bisiklet paylaşım şirketi bulunmaktaydı. Yerel yönetimlerin konuya esnek yaklaşımında bir sonucu olarak Çin genelinde Temmuz 2017'de 16 milyon bisikletin olduğu tahmin ediliyordu. Bu sayının hızlı artışına bağlı olarak Pekin, Şanghay, Wuhan ve Nanjing yerel yönetimleri başta olmak üzere 12 şehrin yerel yönetimleri yeni bisiklet girişini durdurma kararı almıştır (Yu ve Shang, 2017; Campbell, 2018).

Almanya dünyadaki en yüksek bisiklet sahipliğine sahip ülkelerdendir. 2015 yılı Pew verilerine göre hanelerin \%80'inin bisikleti bulunmaktadır. Buna rağmen 2018'de sekiz bisiklet paylaşım şirketi Berlin sokaklarına 18.000 'den fazla bisiklet bırakmıştır ve bu 30.000 'in üstüne çıkacağ 1 tahmin edilmiştir. 18.000 bisikleti dahi kaldıramayan Berlin kaldırımlarında düzensiz parklar nedeniyle yayalar için alanın giderek azalmıştır. Bu arada Singapur kökenli oBike şirketi de Münih'te bisikletlerinin yığınlar halinde park edildiği için çoğu hasar gören 6.800 bisikletinden yaklaşık 6.000'ini kullanımdan kaldırmıştır (Dobush, G, 2018). Oxford'da da operatör ve bisiklet sayısının aşırılığına dikkat çekilmiştir (Keown, 2018). 


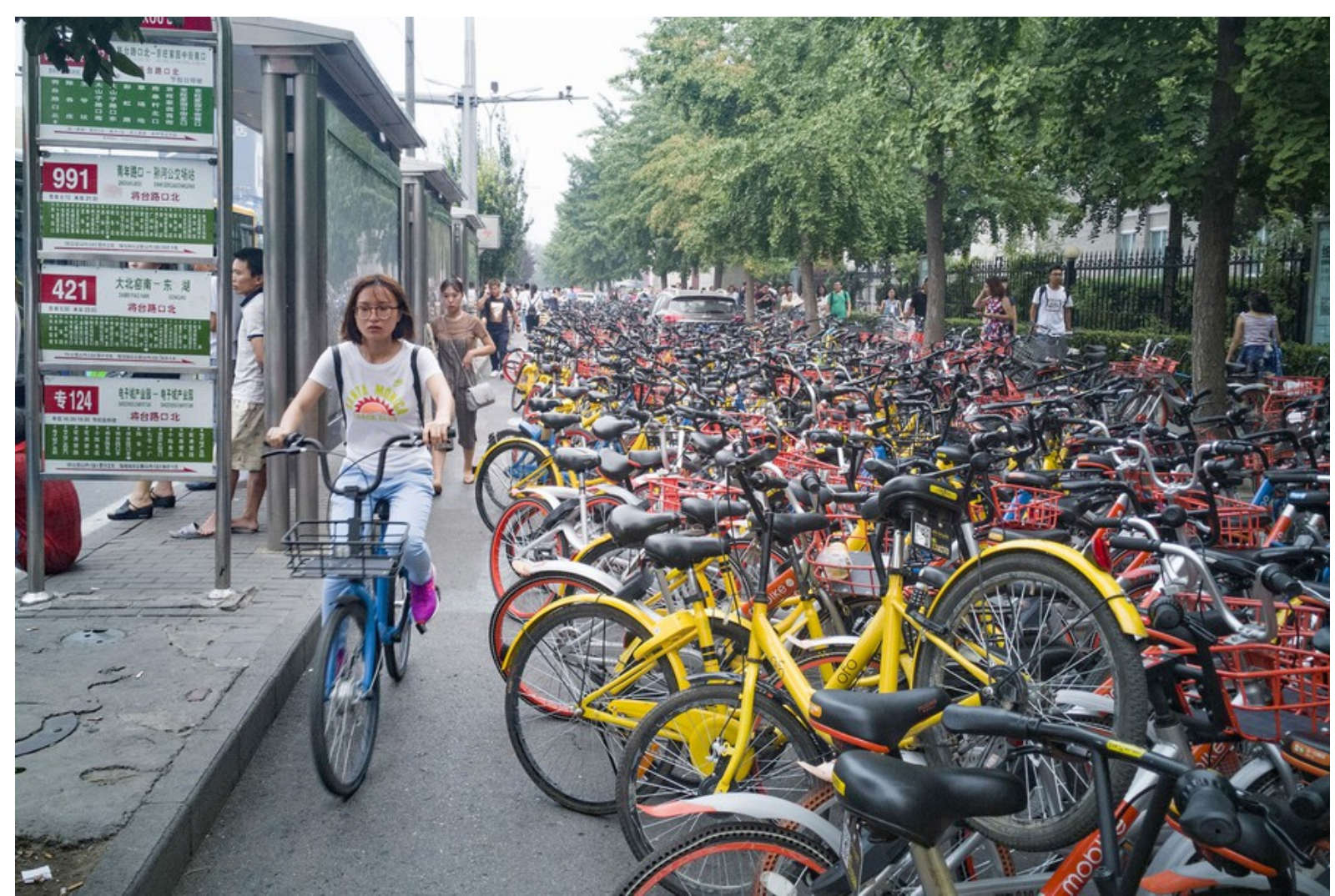

Fotoğraf 10: Pekin'de kaldırımları ve bisiklet yolunu işgal eden düzensiz park edilmiş istasyonsuz paylaşım bisikletleri, 4 Temmuz 2017 (Taylor, 2018).

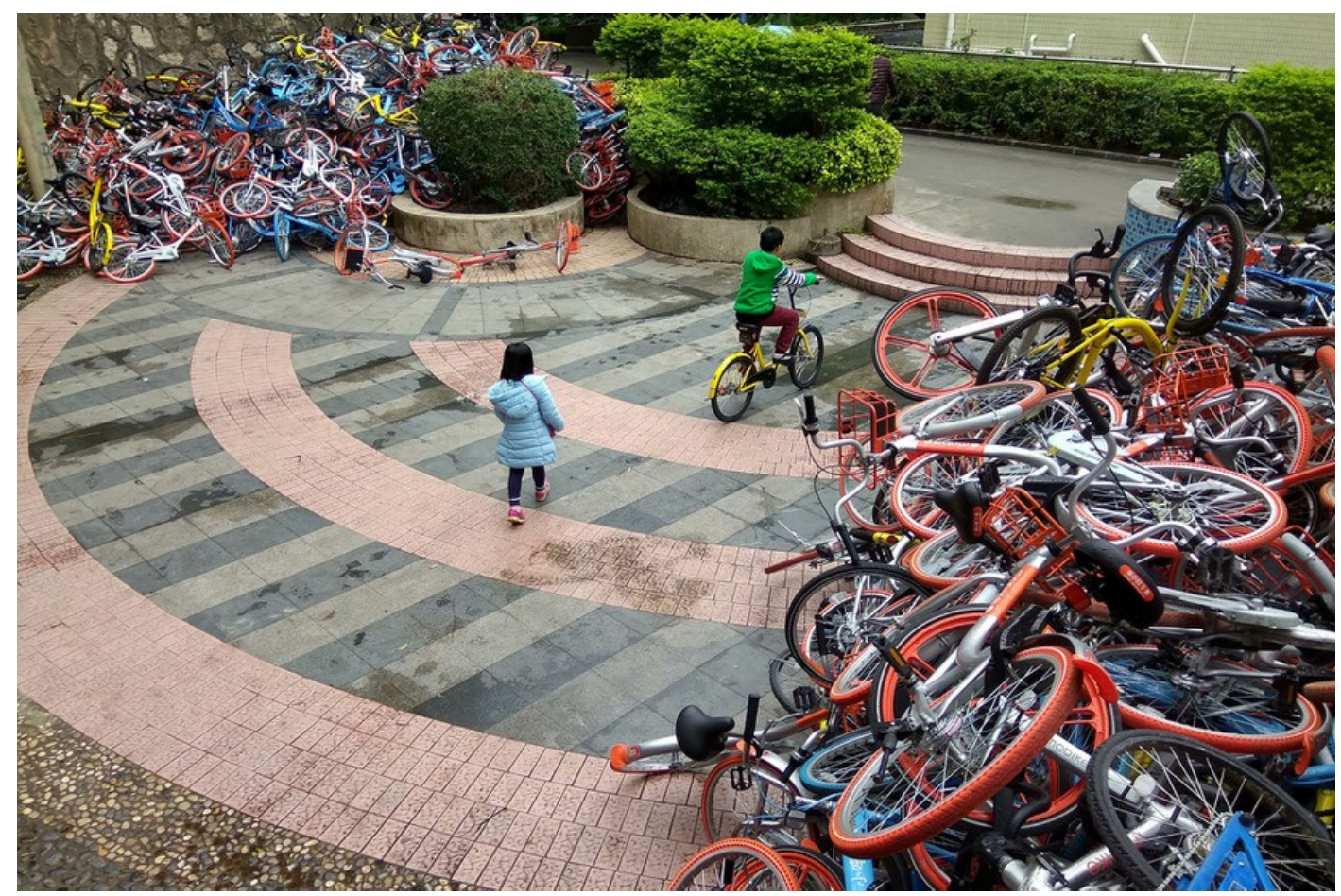

Fotoğraf 11: Bir parkın girişine park edilmiş bisikletler Shenzhen, 16 Ocak 2017 (Taylor, 2018). 
İstasyonsuz paylaşım modasında Paris'in özel bir yeri bulunmaktadır. Paris'in 12 milyonun üzerindeki nüfusu yanında, pandemi öncesinde yıllık yaklaşık 40 milyon turist almıştır; aşırı nüfusa bağlı olarak istasyonlu bisiklerden sonra istasyonsuz bisiklet ve sonrasinda istasyonsuz e-scooter paylaşım firmaları için bir cazibe merkezi olmuştur. Paris yerel yönetimininde istasyonsuz bisikletlere ve e-scooterlara müdahale etmeyen yaklaşımı sonucunda, 2019 yaz sezonunda 10'dan fazla firma Paris sokaklarını her türden araçla doldurmuştur. Paris'de özellikle e-scooter'lar, son derece kısa ömürleri boyunca yeterli getiri sağlayamadıklarından iflaslar peş peşe gelmiştir, çok hızlı pazara giren firmalar çok hızlı şekilde pazardan kaybolmuştur. Gobee, Obike ve Ofo'nun bisiklet paylaşım firmalarının ardından Bosch'un bir iştiraki olan Coup'da Berlin, Paris ve Madrid'deki istasyonsuz scooter paylaşım işini bırakmak zorunda kalmıştır (The Conversation, 2019).

Bazı sektörlerde patentler, yüksek sermaye gereksinimi gibi yeni firmaların sektöre girişini engelleyen bariyerler bulunmaktadır. İstasyonsuz bisiklet paylaşım için bir miktar sermaye, bir web sitesi ve bir uygulama yeterli olmaktadır. Gerekli olan bisikletler veya Scooter'lar Çin'de ucuz bir şekilde üretilmektedir. Hedeflenen şehirlerde bisikletlerin etrafa dağıtılması ile pazara giriş tamamlanmaktadır (The Conversation, 2019). Çin'deki bisiklet paylaşımlarının başarısı yatırımcıların oldukça ilgisini çekmiştir. San Francisco'lu bir şirket olan Crunchbase'in hesaplamalarına göre, dünyanın dört bir yanındaki istasyonsuz bisiklet paylaşım şirketlerine yapılan girişim sermayesi yatırımı, 2016'da 290 milyon dolardan 2017'de 2,6 milyar dolara ulaşmıştır (Belton, 2018). Bu sayede hemen her ülkede rakipler boy göstermeye başlamıştır.

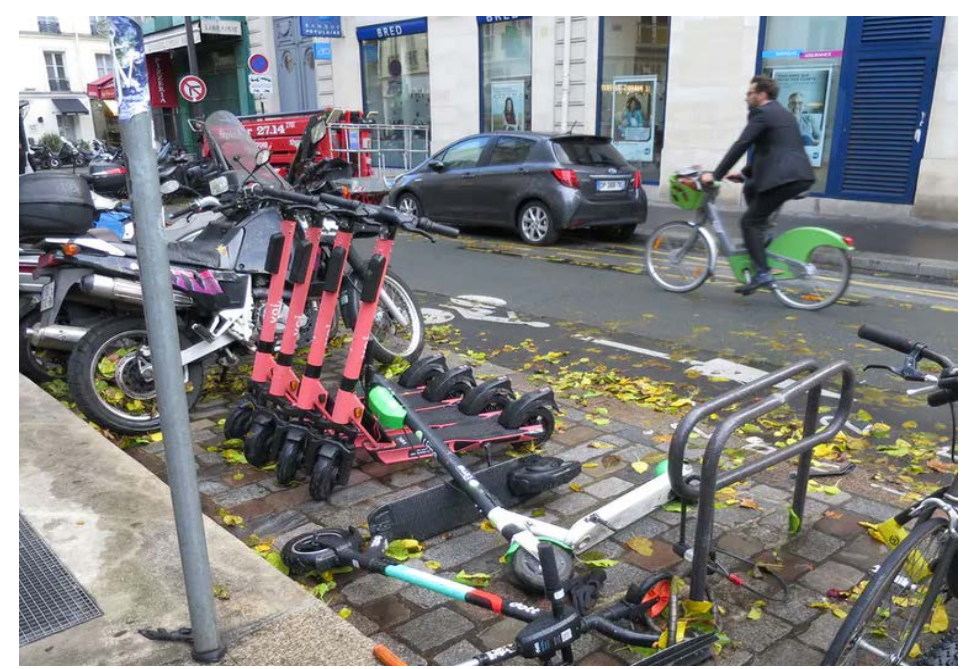

Fotoğraf 12: Paris'te E-Scoterlar

\subsection{Tüketicinin marka değiştirme maliyeti bulunmamaktadır}

İstasyonsuz bisiklet veya E-scooter endüstrilerinde müşteri açısından farklı markalar arasında fiyat dişında bir değiştirme maliyetinden söz edilemez. Avrupa geneli ele alındığında elektronik kilitleri açma maliyetleri genellikle 1 Euro ve dakika başına ücret 0,25 sent civarındadır. Bir markaya ait bir uygulamayı cep telefonuna kurmak için harcanacak zaman dışında, müşterilerin herhangi bir operatöre sadık kalması için hiçbir neden bulunmamaktadır (The Conversation, 2019). Bu bağlamda ilk kayıt esnasında alınan veya 
bloke edilen depozito bedeli bir değiştirme maliyeti olarak düşünülse de uygulamanın iptali ile geri alınabilir nitelikte bir depozitonun bir engel oluşturamayacağı açıktır.

\section{5. Çok sayıda ikame ürün bulunmaktadır}

Birçok büyükşehir toplu taşıma istasyonu ile varış noktası arasındaki problemi çözebilmek için farklı seçenekler geliştirmiştir. Bu seçenekler arasında, diğer istasyonsuz bisiklet paylaşımları dışında; otobüsler, taksiler, araç paylaşım hizmetleri, kişisel bisikletler, kişisel scooter veya kişisel hoverboard'lar sayılabilir. Tüm bunların yanında yürümek de sağlıklı bir alternatiftir (The Conversation, 2019).

\subsection{Firmalar kullanıcılara yeterli güveni telkin edememiştir}

Çin'de Bluegogo ve Coolqi'nin finansal olarak sıkıntıya girmesi, sonrasında 3Vbike'ın kapatılması, halkın istasyonsuz bisiklet paylaşım firmalarından şüphe duymalarına neden olmuştur. İstasyonsuz bisiklet paylaşım firmaları uygulamayı kullanacak müşterilerinden bir depozit almaktadır. Kullanıcıların bir anda depozitlerini geri istemeye başlaması sonucu paylaşım firmaları finansal darboğazlar yaşayarak sonlanmıştır (Yu ve Shang, 2017). 2017'nin sonunda, yukarıdaki üç istasyonsuz bisiklet paylaşım şirketinin iflası sonrasında analistler sektörü patlamaya hazır bir balon olarak değerlendirmekteydiler (Re, 2018). Kasım 2018'de 20 milyon kullanıcısı ve 700.000 bisikleti bulunan Çin'in üçüncü en büyük bisiklet paylaşım girişimi olan Bluegogo müşterilere ve tedarikçilere milyonlarca dolar borçluydu (Campbell, 2018).

\section{SONUÇLAR VE DEĞERLENDİRME}

Herhangi bir istasyona bağlı kalmadan, dilediği yere kadar sürüp sonrasında park etmek için bir istasyon aramadan, bisikletin çalınması endişesi taşımadan bisiklet kullanmak oldukça keyifli olsa gerekir. Bir yandan İnternet, GPS, GPRS ve Bluetooth teknolojilerindeki gelişmeye bağlı bütünleşik sistemlerin maliyetlerindeki düşüş öte yandan elektronik ödeme sistemlerinin akıllı telefon uygulamaları ile bütünleşmesi; istasyonsuz bisiklet paylaşım uygulamalarını mümkün kılmıştır. Çin'den doğan iki firma Ofo ve Mobike birkaç yılda batının birçok şehrinde bir anda yıldızlaşarak sarı ve gümüş renkli bisikletleri ile Çin sokakları yanında batının sokaklarını da neredeyse istila etmişlerdir. Vernon'un Uluslararası Mamul Hayat Eğrisi teorisinin zıddı olan Govindarajan'ın ters inovasyon teorisini destekleyen 4. Nesil bisiklet paylaşım fırtınası o kadar güçlüydü ki Çin resmi haber ajansı ve Çin devlet başkanı Ofo ve Mobike markalarını ayakta alkışlıyorlardı. Milyarlarca dolarlık yatırım alarak, inanılmaz bir hızla yayılan fırtına, vandallığa karşı meydan okuduğu Salford, Manchester'da duvara toslamıştı. Vandallara direnemediği için 14 ay gibi bir sürede Manchester'daki faaliyetlerine son veren Mobike, sonrasında hızlı bir şekilde diğer Avrupa ve ABD pazarlarından da çekilmiştir. Mobike hızla küçülürken Ofo'da vandalim en önemli neden olarak İngiltere pazarından çıkmıştır. Sırasıyla 2 ve 3 milyar US\$ piyasa değerine ulaşan Ofo ve Mobike 2019 yılına gelindiğinde faaliyetlerini sonlandırmışlardı.

Saman alevi gibi parlayıp sönen bu iki firma özellikle bisiklet paylaşım ekonomisinde başarı için önemli ipuçları sağlamıştır. Kullanıcılar paylaşım bisikletleri diledikleri yere park edebiliyorlardı. Ancak bu özgürlük, kullanıcıların gerçekten diledikleri yere park edebilecekleri şeklinde yanlış bir anlaşılmaya yol açarak, kaldırım işgali başta olmak üzere her yere hatalı park etmelerine yol açmıştır. Bisiklet sayısındaki artış şehirlerde kamusal 
alanların arzu edilmeyen şekilde işgaline neden olmuştur. Bisiklet sayılarındaki artışa bağlı olarak, tamir bakım ekipleri arızalı bisikletleri onarıp işler hale getirmekte yetersiz kalmışlardır, anladığımız kadarıyla paylaşım bisikletleri hor kullanıldıkları için arıza olasılıkları da yükselmiştir. Ayrıca, anladığımız kadarıyla firmalar, depozitoları sanki hiç geri istenmeyecekmiş gibi yatırıma dönüştürmüş, büyümek için kullanmışlardı. Ancak kullanıcılar depozitolarını topluca geri istenince, firmalar bunları geri ödeyemeyip finansal çöküntüler yaşadılar. Vandalizm yaygınlığı da paylaşımcılara aşırı güvenmenin hata olduğunu de göstermiştir.

4. nesil bisiklet paylaşım sistemleri hızla yükselip yok olurken farklı ülkelerden 4. nesil bisiklet paylaşımlarından tek farkları scooter kullanmak olan scooter paylaşım sistemlerinin kurulum haberleri gelmeye başlamıştı. Başta İstanbul olmak üzere ülkemizde de adlarını duymaya başladığımız e-scooter paylaşım sistemleri için de yaya kaldırımları işgali ve uygunsuz park şikayetlerinin gazetelerde boy göstermeye başlaması, çalışmamızın uygulamacılar için önemine işaret etmektedir.

\section{KAYNAKÇA}

Bajracharya, L Mulya, T., Purbasari A., and Hwang, M. (2018) A Study on Cost-Effective and Eco-friendly Bicycle Sharing System for Developing Countries, K. J. Kim and N. Baek (eds.), Information Science and Applications 2018, K. J. Kim and N. Baek (eds.), Information Science and Applications, Lecture Notes in Electrical Engineering, 523531.

Belk, R. (2014). You are what you can access: Sharing and collaborative consumption online, Journal of Business Research, 67(8), 1595-1600.

Belton, P. (2018), How cheap dockless hire bikes are flooding the world, BBC, 15 May.

Bork, H. (2019) How short-sighted vision turned a Chinese success story into a cautionary tale, Think: Act Magazine, August 8.

Böcker, L., \& Meelen, T. (2017). Sharing for people, planet or profit? Analysing motivations for intended sharing economy participation. Environmental Innovation and Societal Transitions, 23, 28-39.

Brown, R. (2018). Watch Vandals in bizarre attack on a Cambridge Ofo hire bike. Cambridge News, April 19. https://www.cambridge-news.co.uk/news/cambridge-news/ofovandals-smash-bike-hire-14546486

Campbell, C. (2018), The Trouble with Sharing: China's Bike Fever Has Reached Saturation Point, Time, April 2, 2018, https://time.com/5218323/china-bicycles-sharing-economy/

Chang, S., Song, R., He, S., \& Qiu, G. (2018). Innovative bike-sharing in China: Solving faulty bike- sharing recycling problem. Journal of Advanced Transportation, 2018, 1-10.

Chen, Z., Lierop, D. V., \& Ettema, D. (2020). Dockless bike- sharing systems: what are the implications?. Transport Reviews, 40(3), 333-353, DOI: 10.1080/01441647.2019.1710306

Cohen, B., \& Kietzmann, J. (2014). Ride on! Mobility business models for the sharing economy. Organization \& Environment, 27(3), 279-296. 
Davis, L. S. (2014). Rolling along the last mile: Bike-sharing programs blossom nationwide. Planning, 80(5), 10-16.

DeMaio. (2009). Bike-sharing: History, impacts, models of provision, and future. Journal of Public Transportation, 12(4), 41-56.

Dobush, G. (2018), Shared bikes take over Berlin, Handelseblatt, 06.05.

ECNS Wire. (2018), More than 20 of 77 bike-sharing startups closed in China, ECNS Wire. February 11.

Faghih-Imani, A., Eluru, N., El-Geneidy, A. M., Rabbat, M., \& Haq, U. (2014). How land-use and urban form impact bicycle flows: evidence from the bicycle-sharing system (BIXI) in Montreal. Journal of Transport Geography, 41, 306-314.

Ffrench, A. (2019) Dockless bike firm Ofo could abandon Oxford due to financial difficulties, Oxford Mail, 15 January.

Govindarajan, V., \& Trimble, C. (2013). Beyond the idea: How to execute innovation in any organization. St. Martin's Press.

Griffith, E., (2018) Rivalry among established Chinese companies and US startups has intensified into a trash-talking land grab involving electric scooters and electric bikes), Wired, February 15. https://www.wired.com/story/the-bike-share-wars-heatup-with-latest-funding

Johnson, I. (2018). Mobike goes up in flames- and the cycle hire firms is NOT happy about it. Chroniclelive, September 3. https://www.chroniclelive.co.uk/news/north-eastnews/mobike-goes-up-flames-cycle-15105131

Karl, (2018). From Mobike to No Bike As Dockless Cycle Operator Rides Off Into the Sunset, Salford Media, September 5, Edited, 9 October 2019. https://salford.media/article/national/from-mobike-to-no-bike-as-dockless-cycleoperator-rides-off-into-the-sunset-r1164/

Keown C. (2018), Oxford dockless bike firms set to flood the city with more bikes, OxfordMail, 5 February.

Kim, H., \& Cho, Y. (2018). Analysis of the bicycle-sharing economy: Strategic issues for sustainable development of society. The Journal of Distribution Science, 16(7), 5-16.

Kişi, N. (2018), Paylaşım Ekonomisinin Ulaşım Sektörüne Yansımaları: Uber Örneği. Uluslararası Yönetim ve Sosyal Araştırmalar Dergisi, 5, (10), 57-68

Kohlbacher, F. (2005). The Use of Qualitative Content Analysis in Case Study Research, Forum Qualitative Sozialforschung/Forum: Qualitative Social Research, v.7(1), Art. 21.

Kollewe, J. \& McIntyre, N. (2019), Ofo cycle hire firm pulls out of London, The Guardian Thursday, 10 January.

Lindsay, K. (2018). Mobike dramatically reduces size of cycling zone in Newcastle and Gateshead, Chronicle, 21 September. 
Ma, Y., Rong, K., Mangalagiu, D., Thornton, T. F., \& Zhu, D. (2018). Co-evolution between urban sustainability and business ecosystem innovation: Evidence from the sharing mobility sector in Shanghai. Journal of Cleaner Production, 188, 942-953.

Mair, J., \& Reischauer, G. (2017). Capturing the dynamics of the sharing economy: Institutional research on the plural forms and practices of sharing economy organizations. Technological Forecasting and Social Change, 125, 11-20.

Manzi, G., \& Saibene, G. (2018). Are they telling the truth? Revealing hidden traits of satisfaction with a public bike-sharing service. International Journal of Sustainable Transportation, 12(4), 253-270.

Marangoz, M., Bayrakdaroğlu, F., \& Aydın, A. E. (2017). Tüketimde Alternatif Bir Yaklaşım Olarak Paylaşım Ekonomisi: Ortak Kullanım Ağlarının İçerik Analizi ile İncelenmesi. Dumlupınar Üniversitesi Sosyal Bilimler Dergisi, (Pazarlama Kongresi Özel sayısı), 134-148.

Massey, J. (2017). Yellow army! Dockless bike share company Ofo to launch in Norwich. Eastern Daily Press, October 30.

Mi, Z., \& Coffman, D. M. (2019). The sharing economy promotes sustainable societies. Nature communications, 10(1), 1-3. https://doi.org/10.1038/s41467-019-09260-4

Midgley, P. (2011). Bicycle-sharing schemes: enhancing sustainable mobility in urban areas. United Nations, Department of Economic and Social Affairs, 8, 1-12.

Nielsen, B. (1993). The Bicycle in Denmark: Present Use and Future Potential. Ministry of Transport.

Ngo, H. (2021), Why some bike shares work and others don't, BBC, $13^{\text {th }}$ January https://www.bbc.com/future/article/20210112-the-vast-bicycle-graveyards-of-china

Pidd, H. (2018), Mobike pulls out of Manchester citing thefts and vandalism The Guardian Wednesday 5 September.

Pucher, J., \& Buehler, R. (2008). Cycling for everyone: Lessons from Europe, transportation research record. Journal of the Transportation Research Board, 2074, 58-65.

Re, L.L., (2018), Dockless Bike-Sharing is Reshaping Cities - But We're Not Sure How Yet. TheCityFix, February 8.

Rendaje, M. (2021). https://reviewlution.ca/resources/sharing-economy-statistics/, (15.11.2021).

Salmon, F. (2018), Bring On the Bikocalypse Wired Magazine , 02.01.2018 www.wired.com/story/chinese-dockless-

bikesrevolution/?mbid=BottomRelatedStories

Saunders, M., Lewis, P., \& Thornhill, A. (2012). Research methods for business students Harlow: Pearson.

Shaheen, S. A., Guzman, S., \& Zhang, H. (2010). Bike sharing in Europe, the Americas, and Asia: past, present, and future. Transportation Research Record, 2143(1), 159-167. 
Shaheen, S., Chan, N., 2016. Mobility and the sharing economy: potential to facilitate the first- and last-mile public transit connections. Built Environment, 42 (4), 573-588.

Shaheen, S., Cohen, A. P., \& Martin, E. W. (2013). Public bike sharing in North America: Early operator understanding and emerging trends. Transportation Research Record, 2387, 83-92. doi:10.3141/2387-10

Shead, S. (2017). A Chinese bike-sharing startup is launching in the UK after raising $\$ 600$ million. Business Insider, Jun 16, https://www.businessinsider.com/mobike-uk-bikesharing-2017-6/commerce-on-business-insider

Shi, J. G., Si, H., Wu, G., Su, Y., \& Lan, J. (2018). Critical factors to achieve dockless bikesharing sustainability in China: A stakeholder-oriented network perspective. Sustainability, 10(6), 2090.

Statista, (2020) Value of the sharing economy worldwide in 2014 and 2025 (https://www.statista.com/statistics/830986/value-of-the-global-sharing-economy/) (Erişim: 13.11.2021)

Supriyo, G. (2017). Dynamic Repositioning to Reduce Lost Demand in Bicycle Sharing System. Journal of Artificial Intelligence Research. 58, 387-430.

S.D. Parkes, Marsden, G., Shaheen, S.A. \&. Cohen A.,P. (2013). Understanding the diffusion of public bike sharing systems: evidence from Europe and North America. Journal of Transport Geography, 31, 94-103

Talbot, D. (2019,). 4 problems with dockless bike schemes, and how to solve them, Joyride, February 1, https://joyride.city/blog/hitting-the-wall-4-problems-with-dockless-bikeschemes-and-how-to-solve-them-html/

Tan, X. \& Dafei, Y. (2018) Bike-sharing data and cities: lessons from China's experience, January 17, https://www.thegef.org/blog/bike-sharing-data-and-cities-lessons-china'sexperience\#.Wmm1qwGA-D0.twitter

Taylor, A. (2018). China: Huge Piles of Abandoned and Broken Bicycles, March 22, https://www.theatlantic.com/photo/2018/03/bike-share-oversupply-in-china-hugepiles-of-abandoned-and-broken-bicycles/556268/

Taylor, A. (2018). Bike Share Oversupply In China: Huge Piles Of Abandoned And Broken Bicycles, The Atlantic, March 22, (Erişim: 29.09.2021)

The Conversation (2019), E-scooters, bikes and urban mobility: lessons from the streets of Paris, The Conversation, November 21, https://www.manchestereveningnews.co.uk/news/greater-manchester-news/mobiketheft-vandalism-attacks-manchester-1331446

Velocitta (2021), Better use of bicycle share system http://velo-citta.eu/news/bike-sharingsince-1890-in-india/, (Erişim: 13.10.2021)

Wilmington Bike Share Feasibility Study Ch.3 Risks and Benefits of Bike Share, https://www.wilmingtonde.gov/government/city-departments/planning-and development/bike-wilmington/bike-share-feasibility-study, Spring 2016. 
Yin, J., Qian, L., \& Shen, J. (2019). From value co-creation to value co-destruction? The case of dockless bike sharing in China. Transportation Research Part D: Transport and Environment, 71, 169-185.

Yu D., \& Shang L., (2017), Opportunities and Challenges Faced by Share Economy: Taking Sharing Bicycle as an Example, 2nd International Conference on Modern Economic Development and Environment Protection (ICMED 2017), ISBN: 978-1-60595-518-6.

Zhao, J., Wang, J., \& Deng, W. (2015). Exploring bike sharing travel time and trip chain by gender and day of the week. Transportation Research Part C: Emerging Technologies, $58,251-264$.

Zhao, N., Zhang, X., Banks, M. S. \& Xiong, M. (2018). Bicycle Sharing in China: Past, Present, And Future. Association for Information Systems Conference, Spring 3-23-2018. Atlanta, GA, USA.

Zhou, Z., \& Zhang, Z. J., (2019). Customer satisfaction of bicycle sharing: studying perceived service quality with SEM model. International Journal of Logistics Research and Applications, 22:5, 437-448, DOI: 10.1080/13675567.2018.1513468

\section{İnternet Kaynakları}

https://en.wikipedia.org/wiki/Mobike (Erişim: 16.11.2021)

https://en.wikipedia.org/wiki/Ofo_(company) (Erişim: 16.11.2021)

\section{Videolar}

https://www.manchestereveningnews.co.uk/news/greater-manchester-news/mobike-theftvandalism-attacks-manchester-13314463 (Erişim: 12.11.2021) 